\title{
Impact of ZSM-5 Deactivation on Bio-Oil Quality during Upgrading of Straw Derived Pyrolysis Vapors
}

Eschenbacher, Andreas; Jensen, Peter Arendt; Henriksen, Ulrik Birk; Ahrenfeldt, Jesper; Li, Chengxin; Duus, Jens Øllgaard; Mentzel, Uffe Vie; Jensen, Anker Degn

\section{Published in:}

Energy and Fuels

Link to article, DOI:

10.1021/acs.energyfuels.8b03691

Publication date:

2019

Document Version

Peer reviewed version

Link back to DTU Orbit

Citation (APA):

Eschenbacher, A., Jensen, P. A., Henriksen, U. B., Ahrenfeldt, J., Li, C., Duus, J. Ø., Mentzel, U. V., \& Jensen, A. D. (2019). Impact of ZSM-5 Deactivation on Bio-Oil Quality during Upgrading of Straw Derived Pyrolysis Vapors. Energy and Fuels, 33(1), 397-412. https://doi.org/10.1021/acs.energyfuels.8b03691

\section{General rights}

Copyright and moral rights for the publications made accessible in the public portal are retained by the authors and/or other copyright owners and it is a condition of accessing publications that users recognise and abide by the legal requirements associated with these rights.

- Users may download and print one copy of any publication from the public portal for the purpose of private study or research.

- You may not further distribute the material or use it for any profit-making activity or commercial gain

- You may freely distribute the URL identifying the publication in the public portal 


\section{energy fuels:}

Subscriber access provided by DTU Library

\section{Biofuels and Biomass}

\section{Impact of ZSM-5 deactivation on bio-oil quality during upgrading of straw derived pyrolysis vapors}

Andreas Eschenbacher, Peter Arendt Jensen, Ulrik Birk Henriksen, Jesper Ahrenfeldt, Chengxin Li, Jens Ø. Duus, Uffe Vie Mentzel, and Anker Degn Jensen

Energy Fuels, Just Accepted Manuscript • DOI: 10.1021/acs.energyfuels.8b03691 • Publication Date (Web): 18 Dec 2018

Downloaded from http://pubs.acs.org on December 25, 2018

\section{Just Accepted}

"Just Accepted" manuscripts have been peer-reviewed and accepted for publication. They are posted online prior to technical editing, formatting for publication and author proofing. The American Chemical Society provides "Just Accepted" as a service to the research community to expedite the dissemination of scientific material as soon as possible after acceptance. "Just Accepted" manuscripts appear in full in PDF format accompanied by an HTML abstract. "Just Accepted" manuscripts have been fully peer reviewed, but should not be considered the official version of record. They are citable by the Digital Object Identifier (DOI®). "Just Accepted" is an optional service offered to authors. Therefore, the "Just Accepted" Web site may not include all articles that will be published in the journal. After a manuscript is technically edited and formatted, it will be removed from the "Just Accepted" Web site and published as an ASAP article. Note that technical editing may introduce minor changes to the manuscript text and/or graphics which could affect content, and all legal disclaimers and ethical guidelines that apply to the journal pertain. ACS cannot be held responsible for errors or consequences arising from the use of information contained in these "Just Accepted" manuscripts. 


\section{Impact of ZSM-5 deactivation on bio-oil quality}

\section{2 during upgrading of straw derived pyrolysis vapors}

3 Andreas Eschenbacher ${ }^{1}$, Peter A. Jensen ${ }^{1}$, Ulrik B. Henriksen ${ }^{1}$, Jesper Ahrenfeldt ${ }^{l}$, Chengxin Li $^{2}$,

4 Jens Øllgaard Duus ${ }^{2}$, Uffe V. Mentzel ${ }^{3}$, Anker D. Jensen ${ }^{1 *}$

$5 \quad{ }^{1}$ DTU Chemical Engineering, Technical University of Denmark (DTU), Kgs. Lyngby, DK-2800,

6 Denmark

$7 \quad{ }^{2}$ DTU Chemistry, Technical University of Denmark (DTU), Kgs. Lyngby, DK-2800, Denmark

$8 \quad{ }^{3}$ Haldor Topsøe A/S, Haldor Topsøes Allé 1, DK-2800 Kgs. Lyngby, Denmark

9 KEYWORDS: wheat straw; biomass; fast pyrolysis; H-ZSM-5; deactivation; dealumination; bio-

10 oil; oxygen; NMR characterization; deoxygenation; TAN content

\section{ABSTRACT}

12 In this work, we provide detailed information on the change in product distribution and bio-oil

13 quality during extended feeding of biomass derived fast pyrolysis vapors over ZSM-5. The effect

14 of catalyst deactivation by coking on the resulting oil product characteristics was clarified in order

15 to determine when the vapor upgrading should be stopped and the regeneration initiated. Obtaining

16 a stable catalytic fast pyrolysis (CFP) oil while maintaining good energy recovery is important

17 within the context of potential co-processing these oils with petroleum feedstocks via FCC or 18 hydrotreatment of the whole CFP oil.

19 Wheat straw derived fast pyrolysis vapors were upgraded in an ex-situ fixed bed reactor containing 20 a steamed ZSM-5 catalyst at $500{ }^{\circ} \mathrm{C}$. Oils were collected both for runs starting the upgrading over 
21 a fresh (or regenerated) catalyst, and runs which were continued over an increasingly coked zeolite.

22 The oils were characterized for water content, elemental analysis, total acid number (TAN), 23 chemical composition by GC-MS/FID, size exclusion chromatography (SEC), evaporation 24 characteristics by TGA, ${ }^{1} \mathrm{H}$ NMR, ${ }^{13} \mathrm{C}$ NMR and 2D HSQC NMR spectroscopy.

25 With increasing B:C ratio, the yield of deoxygenated hydrocarbons decreased, accompanied by a 26 breakthrough of primary pyrolysis vapors leading to an increasing organic liquid yield. The oxygen

27 content of the condensed, phase separated oil fraction increased and the molar $\mathrm{O} / \mathrm{C}$ ratio of 0.05 28 and TAN of $6 \mathrm{mg} \mathrm{KOH} / \mathrm{g}$ for oil collected during $\mathrm{B}: \mathrm{C}=0-1.1$ increased to $\mathrm{O} / \mathrm{C}=0.18$ and TAN $29=14 \mathrm{mg} \mathrm{KOH} / \mathrm{g}$ for oil collected during $\mathrm{B}: \mathrm{C}=3.6-6.2$. Oil produced at $90 \%$ reduced catalyst 30 amount and $\mathrm{B}: \mathrm{C}=0-6.5$ and $\mathrm{B}: \mathrm{C}=0-12.9$ increased the carbon recovery into the oil product 31 to $23 \%$ and $27 \%$, respectively, but led to an increase in $\mathrm{O} / \mathrm{C}$ ratio from 0.18 to 0.22 , thus 32 approaching the non-catalytic reference case $\left(\mathrm{SiC}\right.$ bed at $\left.500{ }^{\circ} \mathrm{C}\right)$ of $\mathrm{O} / \mathrm{C}=0.24$. Clear differences 33 in the evaporation behavior of the collected oils were observed, with a shift to more volatile 34 fractions and less charring for products obtained at low B:C ratio. Characterization of the upgraded 35 oils with ${ }^{13} \mathrm{C}$ NMR and ${ }^{1} \mathrm{H}$ NMR indicated a clear enhancement of the aromatics content and a 36 reduction of sugar and aldehyde compounds. The concentration of carbon within carbonyl, 37 carbohydrates and methoxy/hydroxyl groups was effectively reduced for oils obtained at low B:C 38 ratios. Catalyst characterization was performed with $\mathrm{XRF}, \mathrm{NH}_{3}-\mathrm{TPD}, \mathrm{N}_{2}$ and Ar-physisorption, 39 TEM, and XRD. After steaming and four repeated upgrading/regeneration cycles corresponding 40 to an accumulated B:C ratio of 40, the zeolite's concentration of strong acid sites measured by $41 \mathrm{NH}_{3}-\mathrm{TPD}\left(\mathrm{T}_{\text {des }}>300^{\circ} \mathrm{C}\right)$ reduced from $0.43 \mathrm{mmol} / \mathrm{g}$ for the calcined version to $0.07 \mathrm{mmol} / \mathrm{g}$ and 42 the BET surface area decreased from 468 to $385 \mathrm{~m}^{2} / \mathrm{g}$. The hot gas filter upstream the zeolite bed 43 was found effective in preventing accumulation of potassium on the catalyst. 


\section{INTRODUCTION}

45 Catalytic fast pyrolysis (CFP) of biomass has the potential to produce partially upgraded bio-

46 crudes which could be co-processed in existing petroleum refineries by fluid catalytic cracking or

47 hydrotreating to obtain transportation fuels or chemicals. In an ex-situ configuration, the fast

48 pyrolysis (FP) vapors are catalytically upgraded downstream the pyrolysis reactor, which allows

49 to optimize the pyrolysis and upgrading conditions separately. As has been pointed out recently

50 [1], more development and understanding of the catalyst long term stability is necessary. The

51 literature on bench scale ex-situ CFP is scattered in terms of reaction conditions and $\mathrm{B}: \mathrm{C}$ ratio [2-

524 4 hampering a proper evaluation of the process. In order to allow processing of biomass derived

53 FP oils in oil refineries, reduction of the oil's oxygen content and acid number is required [5].

54 Deoxygenation can be obtained by direct upgrading of the pyrolysis vapors over solid acid

55 catalysts. The upgrading process is operated at atmospheric pressure and temperatures close to

56 those for maximum liquid yields in the pyrolysis unit, which offers potential economic advantages

57 for zeolite deoxygenation over high pressure hydrotreating [6]. To date, the medium pore size

58 ZSM-5 zeolite has shown to provide a high aromatic yield and the lowest amount of coke $[7,8]$ in

59 upgrading of pyrolysis vapors. The overall oil yields are drastically reduced at low B:C ratios,

60 since the fresh catalyst promotes cracking reactions which results in increased yields of reaction

61 water, non-condensable gases and coke [10-13]. For blending of CFP oils with fossil oil at

62 refineries, it may be more desirable to increase the energy recovery in the CFP liquid product and

63 accept that not all of the oxygen has been removed. Recent studies obtained promising results for

64 co-feeding catalytic pyrolysis oils containing $\sim 20 \mathrm{wt}-\% \mathrm{db} O$ with fossil derived crude at an FCC

65 unit [6,14-16]. As such, the primary goal of this investigation was not to obtain complete

66 deoxygenation of the collected oil product, but rather to obtain a partial reduction in oxygen

67 content in order to upgrade the primary pyrolysis oxygenates sufficiently to be considered for 
68 further upgrading in a refinery setting. Wheat straw was chosen in this work, which is known to

69 be a more challenging feedstock than wood and has led to boiler related problems in heat and

70 power applications due to the high content of alkali rich ash [17-19]. As an agricultural residue,

71 wheat straw is an economically attractive feedstock. The direct contact during catalytic pyrolysis

72 between straw and zeolite would lead to rapid ash accumulation and deactivation of the zeolite by

73 the alkaline ash components [20]. This has led to patent applications involving both the

74 pretreatment of the biomass by washing and the washing out of ash deposits from the catalyst after

75 oxidative regeneration $[21,22]$. These additional treatment steps add complexity and costs. While

76 hot gas filtration (HGF) of char fines stabilizes the bio-oil [23] and can be seen as non-catalytic

77 ex-situ upgrading method, the residence time has to be kept short to limit secondary cracking

78 reactions and losses to gas and char.

79 The rate and extent of deactivation of the catalyst in catalytic pyrolysis is a major issue. In CFP, 80 deactivation is mainly attributed to coke deposition, which blocks the pores and poisons the active 81 sites of zeolites [24]. Without HGF, some degree of deactivation by deposition of contaminants 82 (ash) originally present in the biomass cannot be excluded either [25]. The rapid decay in site 83 accessibility and number requires frequent regeneration to recover activity. In addition, irreversible 84 dealumination can be caused by steam from i) the pyrolysis process itself, ii) the dehydration 85 reactions during upgrading, and iii) oxidative regeneration. With increasing coke formation on the 86 zeolite, the lumped liquid product is comprised of fully de-oxygenated products obtained at low 87 B:C ratio and products from the breakthrough of primary pyrolysis vapors [26]. Some work has 88 been conducted concerning multiple regeneration/upgrading cycles and investigating the change 89 in oil quality with increasing catalyst deactivation $[10,20,27,28]$ for CFP of woody biomass. These 90 studies concluded that the production of monocyclic aromatics was reduced at increasing B:C ratio 
91 and oxygen containing compounds were converted less efficiently over a partially deactivated 92 catalyst, which was attributed to loss of Brønsted acidity. The coke formation was found to be 93 considerably faster during the initial upgrading [10,11,20] and Horne and coworkers [8] suggested 94 that a partial regeneration of the catalyst may be more effective as it would reduce the initial high 95 losses of the pyrolysis vapors (to coke and non-condensable gases) when passed over the fresh 96 ZSM-5. Noteworthy, these authors worked in a similar scale as this work using 200 g ZSM-5 97 supported on a clay binder in a fixed bed reactor downstream a fluidized sand bed for pyrolysis 98 (wood shavings feeding rate $=222 \mathrm{~g} / \mathrm{h}$ ). Liquid products were collected at certain intervals 99 corresponding to approximate B:C intervals of $0-0.5,0.5-1,1-2$ and $2-3$, respectively. The 100 oxygen content of the oil phase (on wet basis) increased from $15.4 \mathrm{wt}-\%$ obtained in the first 101 upgrading interval to $25.7 \mathrm{wt}-\%$ during the last interval. It should be stressed that none of these 102 studies considered steaming of the catalyst prior to the multiple upgrading/regeneration cycles. For 103 the freshly calcined zeolite, initially a high rate of dealumination can be expected upon exposure 104 to hydrothermal conditions. Thus, upon start of the vapor upgrading the catalyst activity may 105 decrease both due to coke deposition and simultaneous dealumination. Ong et al. [29] varied the 106 steaming duration of ZSM-5 $(\mathrm{Si} / \mathrm{Al}=87)$ from 2 to $48 \mathrm{~h}$ under $100 \%$ steam at $450{ }^{\circ} \mathrm{C}$ in order to 107 investigate the extent of dealumination. While the concentration of Lewis acid sites remained 108 almost constant during the steam treatment, the number of Brønsted acid sites decreased steeply 109 reaching half its initial value after $19 \mathrm{~h}$ of steaming, but thereafter weakened only slowly reaching $110 \sim 41 \%$ of its initial value after $48 \mathrm{~h}$ of steaming. The textural properties were reported to remain 111 unchanged and the crystallinity decreased only by $6 \%$ after $48 \mathrm{~h}$ of steaming. Corma et al. [30] 112 studied the catalytic cracking of naphtha over ZSM-5 with Si/Al ratios of 15,25 and 40 at $650{ }^{\circ} \mathrm{C}$ 113 and a steam vapor fraction between $0 \%$ and $35.7 \%$. Their catalyst underwent intense dealumination 
114 in the presence of steam as determined by IR pyridine measurements and the initial dealumination 115 rate decreased with increasing Si/Al ratio. Similarly, steaming of a ZSM-5 with Si/Al $\sim 11.5$ for 2 $116 \mathrm{~h}$ at $800{ }^{\circ} \mathrm{C}$ with 80 vol- $\%$ steam in $\mathrm{N}_{2}$ carrier gas was found to reduce the amount of strongly 117 adsorbed $\mathrm{NH}_{3}\left(\mathrm{~T}_{\mathrm{des}}>300{ }^{\circ} \mathrm{C}\right)$ to about $7 \%$ of its initial value [31].

118 The optimal molar Si/Al ratio for CFP of biomass appears to be in the range of $11.5-40$ [32]. 119 Paasikallio and coworkers [20] used $95 \mathrm{~kg}$ of spray-dried HZSM-5 catalyst (CBV 5524G) for 120 catalytic upgrading of 2 tons of pine sawdust during a four-day test run in a circulating fluidized121 bed reactor. The acidity of the used catalyst was found to decrease as a function of its alkali metal 122 content $(\mathrm{K}, \mathrm{Ca}, \mathrm{Mg})$ and $\mathrm{P}$. However, it appears difficult to discern to what extent the loss in 123 catalyst acidity resulted from the poisoning of acid sites by alkali metals introduced with the 124 biomass or from the dealumination by steam during the vapor upgrading $\left(520^{\circ} \mathrm{C}\right)$ and regeneration 125 procedure $\left(660^{\circ} \mathrm{C}\right)$.

126 Lower $\mathrm{Si} / \mathrm{Al}$ ratios result in higher acid site density and may result in higher aromatic yields and 127 more severe deoxygenation [33]. However, as was shown by Wan [34], the increased acid site 128 density leads to increased deactivation rates for aromatic products and higher coking rates. The 129 reason for researchers to opt for higher $\mathrm{Si} / \mathrm{Al}$ ratios of e.g. 40 is likely related to the enhanced 130 hydrothermal stability of ZSM-5 with lower Al content.

131 In this work, a series of successive upgrading steps of wheat straw derived FP vapors over a 132 steamed ZSM-5 with $\mathrm{Si} / \mathrm{Al}=29.5$ was performed. Liquid product was collected in between the 133 upgrading steps in order to unravel the change in oil-quality and yield towards increasing B:C ratio 134 and catalyst deactivation. Changes in oil properties was followed by analyzing for moisture, 135 elemental composition, GC-MS/FID and acidity. For selected samples, detailed analysis by NMR, 136 SEC and TGA simulated distillation was performed. 


\section{EXPERIMENTAL SECTION}

138 Feedstock and catalyst. Wheat straw pellets were ground and sieved to pass a $1.4 \mathrm{~mm}$ sieve.

139 The results of proximate and ultimate straw composition are shown in Table 1. The content of 140 moisture, ash, and volatiles was determined according to DS/EN ISO 18134-3 (2015), DS/EN ISO 14118122 (2015), and DS/EN ISO 18123 (2015) respectively, and fixed carbon was calculated by 142 difference. The proximate and ultimate ash analysis by ICP and Chlorine extraction was carried 143 out by Force Technology, Denmark. Elemental analysis of the N, C, H and O content (by 144 difference) was performed in-house with a EuroVector EA3000 system. The accurately weighed 145 sample ( $\sim 2 \mathrm{mg})$ was loaded into a tin capsule and combusted at $980{ }^{\circ} \mathrm{C}$. The combustion products $146\left(\mathrm{~N}_{\mathrm{x}} \mathrm{O}_{\mathrm{y}}, \mathrm{CO}_{2}, \mathrm{H}_{2} \mathrm{O}\right.$ and $\left.\mathrm{SO}_{2} / \mathrm{SO}_{3}\right)$ passed through a reduction reactor and were converted into $\mathrm{N}_{2}$, $147 \mathrm{CO}_{2}, \mathrm{H}_{2} \mathrm{O}$, and $\mathrm{SO}_{2}$ and subsequently analyzed by GC-TCD. Acetanilide and sulphanilamide were 148 used as calibration standards. The higher heating value of biomass and liquid products was 149 calculated based on the formula developed by Channiwala et al. [35], taking the elemental 150 composition and ash content into account. Measurement of the heating value of the feedstock using 151 a Parr 6300 Oxygen bomb calorimeter resulted in $2-10 \%$ lower HHV-values compared to the 152 calculated value. This is partly attributed to adsorption of atmospheric moisture prior to analysis. 153 Notably is the high potassium content of the feedstock which is known to have a catalytic effect 154 in promoting char and gas formation during pyrolysis [36].

Table 1. Properties of crushed wheat straw and pine wood pellets

\begin{tabular}{|l|c|c|}
\hline Proximate analysis [wt \%] & $\begin{array}{l}\text { wheat } \\
\text { straw }\end{array}$ & pine wood \\
\hline Moisture [a.r.] & $6.2 \%$ & $4.3 \%$ \\
\hline Volatiles [d.b.] & $75.5 \%$ & $82.4 \%$ \\
\hline Ash [d.b.] & $5.9 \%$ & $0.2 \%$ \\
\hline
\end{tabular}




\begin{tabular}{|l|c|c|}
\hline Fixed carbon (by difference) & $17.4 \%$ & $13.1 \%$ \\
\hline $\mathrm{HHV}_{\text {daf }}[\mathrm{MJ} / \mathrm{kg}]$ & 19.2 & 19.8 \\
\hline Ultimate analysis [wt\% d.b.] & & \\
\hline $\mathrm{N}$ & $0.9 \%$ & $0.2 \%$ \\
\hline $\mathrm{C}$ & $46.5 \%$ & $51.5 \%$ \\
\hline $\mathrm{H}$ & $6.7 \%$ & $6.2 \%$ \\
\hline $\mathrm{O}$ & $45.8 \%$ & $41.9 \%$ \\
\hline $\mathrm{S}$ & $0.08 \%$ & $0.007 \%$ \\
\hline $\mathrm{Cl}$ & $0.11 \%$ & $0.016 \%$ \\
\hline $\mathrm{Al}$ & $0.02 \%$ & $0.003 \%$ \\
\hline $\mathrm{Ca}$ & $0.32 \%$ & $0.095 \%$ \\
\hline $\mathrm{Fe}$ & $0.01 \%$ & $0.003 \%$ \\
\hline $\mathrm{K}$ & $0.98 \%$ & $0.048 \%$ \\
\hline $\mathrm{Mg}$ & $0.07 \%$ & $0.014 \%$ \\
\hline $\mathrm{Na}$ & $0.01 \%$ & $0.010 \%$ \\
\hline $\mathrm{P}$ & $0.11 \%$ & $0.005 \%$ \\
\hline $\mathrm{Si}$ & $1.10 \%$ & $0.020 \%$ \\
\hline
\end{tabular}

156

157 A ZSM-5 sample with a Si/Al ratio of 29.5 (CBV5524) was obtained from Zeolyst International.

158 It will be abbreviated CBV55 and steaming, biomass pyrolysis vapor upgrading and regeneration

159 is indicated by adding the suffixes "st", " $\mathrm{u}^{\mathrm{x}}$ ", and " $\mathrm{r}^{\mathrm{y} \text { ", }}$, respectively, with the exponents $\mathrm{x}$ and $\mathrm{y}$

160 denoting the number of previous upgrading and regeneration steps the sample underwent. The

161 zeolite powder in ammonium form was calcined under synthetic air flow for $5 \mathrm{~h}$ at $550{ }^{\circ} \mathrm{C}$ with a

162 heating ramp of $4{ }^{\circ} \mathrm{C} / \mathrm{min}$. The calcined zeolite was pelletized, crushed and sieved to obtain the

163 fraction between 250 to $850 \mu \mathrm{m}$. In order to collect sufficient liquid product for analysis at low

$164 \mathrm{~B}: \mathrm{C}$ ratios $151 \mathrm{~g}$ of dry catalyst with a catalyst volume of $335 \mathrm{ml}$ were packed as a fixed bed into

165 the externally heated reactor $(\mathrm{ID}=67 \mathrm{~mm}$, length $=250 \mathrm{~mm})$. Tests at higher $\mathrm{B}: \mathrm{C}$ ratio up to 12.9 
166 were performed using $15 \mathrm{~g}$ of catalyst ( $33.5 \mathrm{ml}$ catalyst volume) packed into a smaller externally 167 heated reactor tube (ID $=20 \mathrm{~mm}$, length $=190 \mathrm{~mm}$ ). For both reactor sizes, quartz wool and 168 perforated distribution plates were placed between the catalyst bed and gas-inlet/outlet pipes in 169 order to ensure plug flow behavior and avoid channeling or dead pockets. Steaming was performed 170 in situ prior to the upgrading reaction by injecting water into a preheated nitrogen stream (4 $171 \mathrm{Nl} / \mathrm{min})$ and passing the steam $(\sim 30 \mathrm{vol}-\%)$ over the zeolite bed kept at $500{ }^{\circ} \mathrm{C}$ for $5 \mathrm{~h}$ under 172 atmospheric pressure conditions.

173 Pyrolysis unit. A bench scale ablative type fast pyrolysis set-up was modified from previous 174 work [37] according to Scheme 1. The centrifugal reactor chamber is a horizontally arranged tube, 175 with rotating arch shaped blades providing mechanical force on the biomass particles pressing 176 them onto the inside of the reactor wall. Previous experience with fast pyrolysis of straw using the 177 centrifugal reactor [1] resulted in uncertainties ( \pm 2 standard deviations) for the product yields of 178 organic oil, reaction water, char, and gas, of $0.7,0.7,3.8$, and $1.5 \mathrm{wt}-\%$ daf, respectively. Compared 179 to previous work, an electrostatic precipitator (ESP) was added to improve the collection of 180 aerosols, and on-line gas analysis of non-condensable gasses was added. The pyrolysis unit can 181 process a feeding rate up to $\sim 8 \mathrm{~g} / \mathrm{min}$ of biomass. For tests carried out in this work, the feeding 182 rate was in the range $1-1.6 \mathrm{~g} / \mathrm{min}$, which allowed stable upgrading of pyrolysis vapors and 183 condensation. The nitrogen carrier gas was preheated to $450{ }^{\circ} \mathrm{C}$ and the temperature inside the 184 centrifugal reactor was set to $530^{\circ} \mathrm{C}$. Char particles and fines were captured by a change-in-flow 185 separator, a cyclone, and a ceramic candle filter. Downstream the catalytic reactor the vapors were 186 immediately quenched in a condenser kept at $4{ }^{\circ} \mathrm{C}$. The aerosols generated at the initial 187 condensation stage were captured with the ESP. Downstream the ESP unit the gas stream passed 188 through a series of glass cold fingers immersed in a dry ice/ethanol bath $\left(-60^{\circ} \mathrm{C}\right)$. Any remaining 
189 traces of condensable compounds were captured by a glass tube filled with rockwool. The flow of 190 non-condensable gases was monitored with a cumulative flow meter. A side stream of non191 condensable gases was pumped through a filter to an online gas chromatograph (Thermo Scientific 192 refinery gas analyzer, Trace 1300/1310) with a flame ionization detector (FID) and two thermal 193 conductivity detectors (TCD), which measured the gas composition $\left(\mathrm{H}_{2}, \mathrm{~N}_{2}, \mathrm{CO}, \mathrm{CO}_{2}, \mathrm{C}_{1}\right.$ to $\mathrm{C}_{5}$, 194 and $\mathrm{C}_{6+}$ hydrocarbons) every 10 minutes. Chromeleon Chromatography Studio software was used 195 for analysis of the chromatograms. A Rosemount NGA 2000 analyzer was used to continuously 196 monitor $\mathrm{CO}$ and $\mathrm{CO}_{2}$ by NDIR, and $\mathrm{O}_{2}$ by paramagnetism.

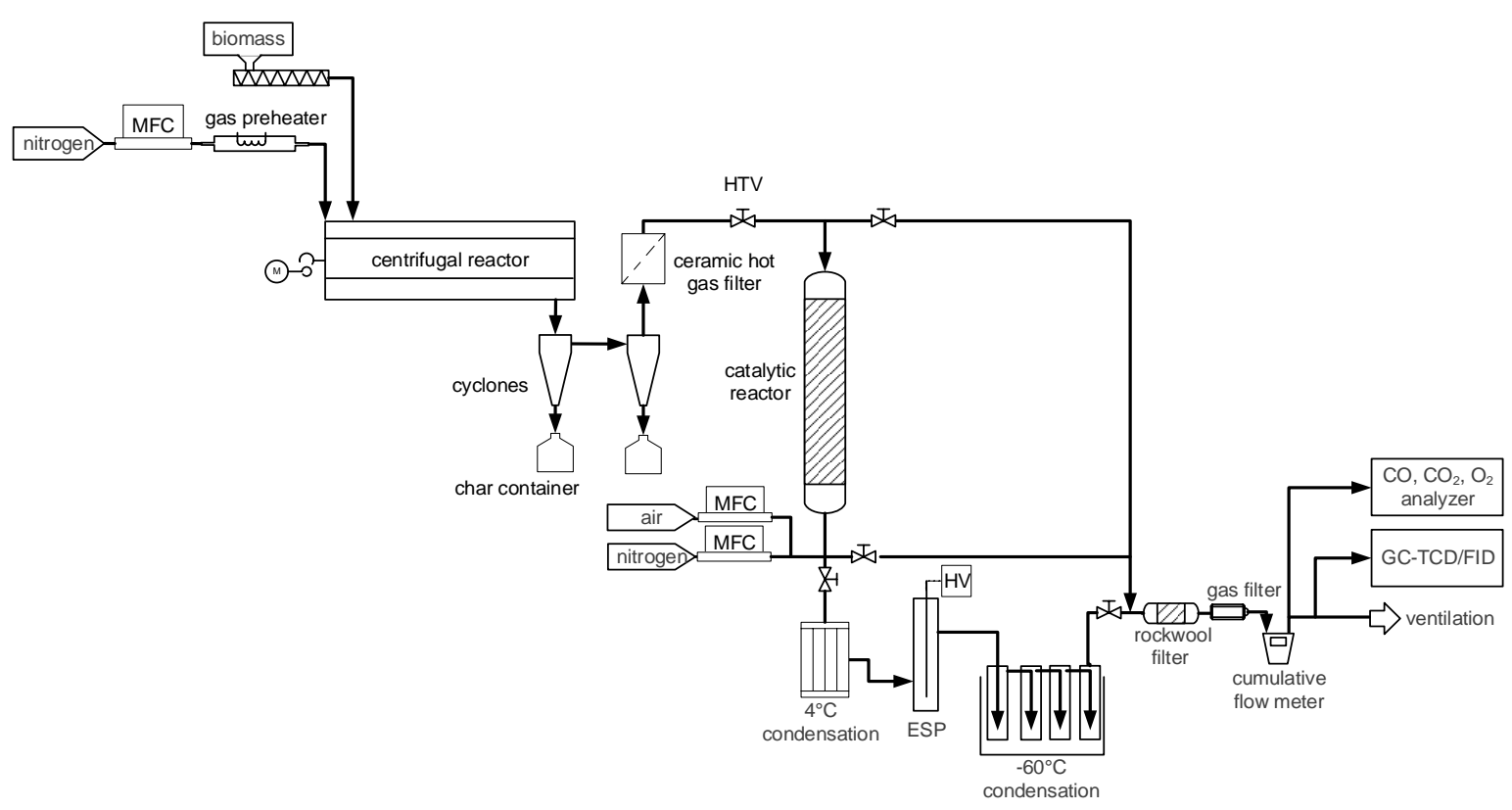

198 Scheme 1. Pyrolysis unit with ex-situ fixed bed catalytic reactor for upgrading of vapors.

199 Experimental procedure. Prior to each experimental run, the system was leak tested. The 200 cooling of the condensation train was started once the reactor system was preheated and flushed 201 sufficiently to avoid condensation of residual moisture. Once stable temperature and gas profiles 202 were established, the experiment was initiated by starting the motor and screw feeder. The rotation 203 speed of the blades in the pyrolysis reactor was set to $1700 \mathrm{rpm}$ and a nitrogen carrier flow of 8 
$204 \mathrm{Nl} / \mathrm{min}$ was used and the biomass feeding rate was in the range $1-1.6 \mathrm{~g} / \mathrm{min}$. The temperature of 205 the pyrolysis unit, particle separation train and catalyst bed were set to $530{ }^{\circ} \mathrm{C}, 400{ }^{\circ} \mathrm{C}$, and 500 $206{ }^{\circ} \mathrm{C}$ respectively. The temperature distribution along the length of the catalyst bed was measured 207 with three thermocouples placed at the beginning, middle and end of the bed, and the difference 208 between bed entry and exit was approximately $10^{\circ} \mathrm{C}$ (lower temperature at bed entry). The piping 209 and high temperature valve upstream the reactor was heat traced to approximately $450{ }^{\circ} \mathrm{C}$ in order 210 to preheat the gas before entering the catalyst bed. The screw feeder and the operation of the rotary 211 reactor were stopped when the desired experimental time was reached. Any remaining vapors were 212 flushed for about 60 min while maintaining the operating temperatures in the system. The amount 213 of non-condensable gases (NCG) was determined by the GC analysis using nitrogen as internal 214 standard. After flushing of the system, the condensation train was bypassed and the system was 215 cooled to room temperature under nitrogen flow to prevent air diffusion into the system. The 216 amount of collected products was determined gravimetrically by weighing all condensation 217 equipment. For the first cooling stage operating at $4{ }^{\circ} \mathrm{C}$, phase separation into an aqueous phase 218 and an oil/tarry phase could occur. Since the viscous oil stuck to the walls and bottom of the metal 219 condensers, the water phase could be carefully decanted. The remaining oil fraction was 220 determined by weighing of the equipment plus tarry residues. In the following, these fractions will 221 be denoted as " $4{ }^{\circ} \mathrm{C}$ WF" and " $4{ }^{\circ} \mathrm{C} \mathrm{OF"} \mathrm{for} \mathrm{the} \mathrm{aqueous} \mathrm{and} \mathrm{oil} \mathrm{fraction,} \mathrm{respectively.} \mathrm{For} \mathrm{the} \mathrm{ESP}$ 222 unit the oil was collected at a bottom receiver, and no phase separation occurred. The ESP oil will 223 be termed "ESP OF". For the final condensation step at $-60^{\circ} \mathrm{C}$, the collected product separates 224 upon melting into an aqueous phase (bottom) and a yellowish oil phase (top). We will refer to 225 these fractions as " $60^{\circ} \mathrm{C} \mathrm{WF}$ " and " $-60^{\circ} \mathrm{C}$ OF", respectively. The glass condensers were emptied 226 into a measuring flask and the split between oil and water phase was determined by removing the 
227 oil top phase with a pipette. Since the sum of residues remaining in the glass condensers amounts

228 to less than $5 \%$ of the total liquid collected at this condensation stage, it was assumed that the

229 traces of oil/water droplets remaining in the condensers consist of the same split between oil and

230 water fraction as determined for the removed liquid. Due to the effectiveness of the condensation

231 train, the gas filters downstream the condensation system did not capture liquid product. Residues

232 sticking to the condensation equipment were not flushed by solvent in order to avoid the

233 introduction and necessity of removal of the solvent. Thus, the operation at bench scale allowed

234 the collection of larger amounts of liquids, which reduced the potential handling and analysis errors

235 related to the collection of small amounts of oil product. After flushing the system at the operating

236 temperature, the catalyst bed was cooled down to $\sim 200{ }^{\circ} \mathrm{C}$ in a nitrogen flow. Once the high

237 temperature valve (HTV in Scheme 1) was closed and the condensation train bypassed, the flow

238 was reversed to enter the reactor bed from the outlet $(2 \mathrm{Nl} / \mathrm{min})$. The regeneration was initiated by

239 mixing nitrogen with air (flowrate $2 \mathrm{Nl} / \mathrm{min}$ with 2 vol- $\% \mathrm{O}_{2}$ ) and starting a heating ramp to 580

$240{ }^{\circ} \mathrm{C}$ at $1{ }^{\circ} \mathrm{C} / \mathrm{min}$. The set-point was held for several hours before the nitrogen was stepwise replaced

241 by increasing amounts of air to achieve a final oxygen concentration of 21 vol- $\%$. The regeneration

242 was assumed complete once no more $\mathrm{CO}$ and $\mathrm{CO}_{2}$ was measured in the effluent gas stream.

243 Initially an empty reactor test and a non-catalytic reference test was performed over a $\mathrm{SiC}$ bed

244 material $(60 \mathrm{ml}, 355-500 \mu \mathrm{m})$ maintained at $500{ }^{\circ} \mathrm{C}$, both for wheat straw and pine wood

245 feedstock. Subsequently, five vapor upgrading (wheat straw) experiments were conducted as

246 illustrated in Scheme 2 using $151 \mathrm{~g}$ of CBV55 covering the range of B:C ratios up to 6.2.After the

247 initial run to B:C $=1.7$, the coke was burned off. Subsequently, four successive experiments were

248 performed where liquid was collected but no catalyst regeneration was performed. The resulting 249 properties for the mixture of the products obtained within the successive upgrading were calculated 
250 according to their mass yields and elemental composition. As an example, the properties of liquid 251 obtained for $\mathrm{B}: \mathrm{C}=0-2.5$ were estimated by calculating the properties of liquid obtained for 252 mixing product obtained for $\mathrm{B}: \mathrm{C}=0-1.1$ and $\mathrm{B}: \mathrm{C}=1.1-2.5$ according to their mass yields. 253 After the test series using 151 of catalyst, $15 \mathrm{~g}$ of regenerated catalyst was transferred to a smaller 254 reactor and two further upgrading experiments were performed in order to obtain oil at B:C $=0$ 2556.5 and $\mathrm{B}: \mathrm{C}=0-12.9$ (not shown in scheme). The catalyst at the end of the test series thus 256 underwent four oxidative regenerations and will be termed CBV55-st- $\mathrm{u}^{7}-\mathrm{r}^{4}$.

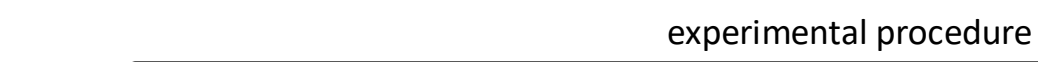

258 Scheme 2. Scheme of experimental test series for conversion of straw pyrolysis vapors over 151

259 g CBV55. Conditions during upgrading: $T_{\text {catalyst }}=500{ }^{\circ} \mathrm{C}, \mathrm{WHSV}=0.64$ g biomass $/\left(\mathrm{g}_{\text {catalyst }} \cdot \mathrm{h}\right), 8$

$260 \mathrm{Nl} / \mathrm{min}_{2}$ flow.

261 Product characterization. To minimize potential ageing reactions, all liquid products were kept 262 refrigerated at $5{ }^{\circ} \mathrm{C}$ after their recovery from the condensation train. The water content of the oil 263 and aqueous phase fractions was determined by Karl Fischer titration (ASTM E203-08). Total acid 264 number determination for selected samples was performed according to ASTM D 664 using an 265848 Titrino plus (Metrohm). The TAN analysis method according to ASTM D664 was verified by 266 analyzing a reference sample obtained for $10 \mathrm{mg} \mathrm{KOH} / \mathrm{g}$ (Paragon Scientific Limited) and proved 267 to correlate within $5 \%$ of the expected value. The elemental composition (nitrogen, carbon, 268 hydrogen) was measured by using an EA3000 CHNS elemental analyzer from Eurovector. For the 
269 sample preparation of aqueous and volatile oil fractions, a special sealing device (Eurovector) and 270 smooth tin capsules were used. Calibration $\left(\mathrm{R}^{2}=0.998\right)$ was performed with acetanilide $(>99 \%)$ 271 and sulphanilamide ( $>99 \%)$. The analysis of liquids was verified by analyzing volatile model 272 compounds (acetone) and water. In general, the time between liquid sample preparation and 273 injection was kept as short as possible and minimum two replicates were performed per sample. 274 The oxygen content was determined by difference. The higher heating value of the bio-oil was 275 calculated based on the elemental composition using an empirical formula according to 276 Channiwala et al. [38]. As the sulfur concentration was below the detection limit of the elemental 277 analyzer, few representative oils were subjected to total sulfur analysis according to ASTM method 278 D5453. All fractions obtained from the different condensation train sections were analyzed 279 separately by using a GC-MS/FID Shimadzu QP 2010 Ultra apparatus equipped with a Supelco 280 Equity 5 column. Identification and quantification of species in the samples was performed by the 281 mass spectrometer and flame ionization detector (FID), respectively. For the analysis, the oil and 282 aqueous fractions were diluted in acetone containing $0.1 \mathrm{~mol} / \mathrm{L}$ heptane as internal reference. The 283 initial temperature for the GC column was held at $80^{\circ} \mathrm{C}$ for $10 \mathrm{~min}$ and the column was heated up 284 to $250{ }^{\circ} \mathrm{C}$ with an initial heating rate of $2{ }^{\circ} \mathrm{C} / \mathrm{min}$ up to $100{ }^{\circ} \mathrm{C}$ followed by an increased heating 285 rate of $5{ }^{\circ} \mathrm{C} / \mathrm{min}$. The final temperature was held for $5 \mathrm{~min}$. A split ratio of 80 was used in the 286 injection section. The MS scanning was set to a range of 20 to $300 \mathrm{~m} / \mathrm{z}$. The MS was intentionally 287 turned off between 2.57 to 2.65 minutes in order to avoid saturation by high concentrations of the 288 solvent. The analysis entails the quantitative determination of $>200$ compounds based on the 289 effective carbon number (ECN) method outlined by Schofield [39]. For the internal standard 290 heptane, a detailed calibration was performed, and the validity of calculated concentrations 291 according to their ECN was periodically verified by calibration of 25 bio-oil model compounds. 
292 The relative error between calculated concentrations and concentrations obtained from the 293 calibration can be found in the supporting information, Table S1. As can be seen, the calculation 294 by the ECN method underestimates the concentration for most of the components. It should be 295 noted that all oil fractions were analyzed with the same GC method. However, since most 296 polycyclic aromatic hydrocarbons like phenanthrene appeared at the end of the chromatogram, 297 higher MW compounds and oxygenates were not quantified. Up to $64 \%$ of the total organic liquid 298 contents could be quantified by GC-MS/FID for oils obtained at low B:C ratio, whereas only 20 $29930 \%$ could be quantified for oils obtained over a coked catalyst after reaching a high B:C ratio. A 300 low quantification extent indicates a shift in product distribution towards less volatile species and 301 higher molecular weight range, which was confirmed by TGA simulated distillation and size 302 exclusion chromatography (vide infra).

303 The GPC system comprises Viscotek Data Manager DM 400, Shimadzu SIL-10AD vp auto304 sampler, Shimadzu LC-10AD pump/injection, 7.5 x 300 mm PLgel MIXED-E from Agilent and 305 two detectors; namely, a Viscotek RALLS (Right Angle Laser Light Scattering), Model 600, Laser 306 Diode Wavelength of 670nm, and a Viscotek Differential Refractometer/Viscometer, Model 200. 307 THF was used as eluent, and the samples were prepared at the day of analysis. The injection 308 volume was $100 \mu \mathrm{l}$ and a flowrate of $0.5 \mathrm{ml} / \mathrm{min}$ was utilized. TriSEC GPC softeware, Version 3.0 309 was used for data export and baseline correction was performed using Origin software. An 310 indication of the approximate molecular weight range was obtained by analysis of a polystyrene 311 standard of $1250 \mathrm{Da}$, several linear hydrocarbon standards covering the range of $200-500 \mathrm{Da}$, 312 toluene (92 Da), and few exemplary bio-oil model compounds (guaiacol (124 Da), dibenzofuran 313 (168 Da), furfural (96 Da), and phentanthrene (178 Da)). All standards were prepared at a 314 concentration of $1.5 \mathrm{mg} / \mathrm{ml}$. Arrows in the chromatogram indicate where the components eluted. 
315 While dibenzofuran, furfural, and phentanthrene eluted in close proximity to toluene $(9.8 \mathrm{ml})$, 316 guaiacol eluted significantly earlier at $9.5 \mathrm{ml}$. This indicates that mono and polyaromatics cannot 317 clearly be distinguished with the set-up used. Branched or multi-functional compounds may elute 318 earlier. As such, no absolute molecular weight determination was attempted.

319 Simulated distillation [40] was used with a heating rate of $50^{\circ} \mathrm{C} / \mathrm{min}$ to fit the results of the D86 320 standard using a TGA (Netzsch Jupiter 449F1). 10 - $20 \mathrm{mg}$ of oil was placed into a Pt crucible 321 with perforated lid after weighing of the empty crucible and immediately before the sample 322 weighing and start of the temperature ramp. The temperature program under $150 \mathrm{Nml} / \mathrm{min}$ nitrogen 323 was set to heat with $50^{\circ} \mathrm{C} / \mathrm{min}$ up to $650{ }^{\circ} \mathrm{C}$, hold the temperature for $5 \mathrm{~min}$ before cooling to 350 $324{ }^{\circ} \mathrm{C}$. The atmosphere was changed to 10 vol- $\%$ oxygen and a heating ramp to $850{ }^{\circ} \mathrm{C}$ was initiated 325 in order to combust char residues.

326 Proton NMR spectra were acquired on Bruker AVANCE $400 \mathrm{MHz}$ spectrometer with a $5 \mathrm{~mm}$ 327 CryoProbe Prodigy using approximately $50 \mathrm{mg}$ sample dissolved in $1 \mathrm{~mL}$ of deuterated dimethyl 328 sulfoxide (DMSO-d6). Quantitative ${ }^{13} \mathrm{C}$ NMR spectra and ${ }^{1} \mathrm{H}-{ }^{13} \mathrm{C}$ HSQC spectra were acquired on 329 a Bruker AVANCE III 800MHz spectrometer with a $5 \mathrm{~mm}$ TCI CryoProbe with $100 \mathrm{mg}$ sample 330 solubilized in $200 \mathrm{~mL}$ of DMSO-d 6 . Both ${ }^{1} \mathrm{H}$ and ${ }^{13} \mathrm{C}$ spectra were recorded at $25{ }^{\circ} \mathrm{C}$ using a $30^{\circ}$ 331 pulse angle. ${ }^{1} \mathrm{H}$ experiments were run with $1 \mathrm{~s}$ delay, 16 scans. ${ }^{13} \mathrm{C}$ NMR were recorded with 332 inverse-gated decoupling, $8 \mathrm{~s}$ delay, 512 scans. The edited phase sensitive ${ }^{1} \mathrm{H}-{ }^{13} \mathrm{C}$ HSQC 333 experiments were recorded with $2048 \times 256$ complex data points, 4 scans. The one-bond coupling 334 constant, $\mathrm{J}_{\mathrm{HC}}$, was set to $145 \mathrm{~Hz}$. Spectral widths in the proton and carbon dimensions were 16 335 ppm and $220 \mathrm{ppm}$, respectively. Transmitter frequency offset of proton and carbon were set at 4.7 336 ppm and 110 ppm, respectively [41]. All NMR spectra were processed with Topspin 3.5 with zero 337 filling in all dimensions. ${ }^{1} \mathrm{H}$ and ${ }^{13} \mathrm{C}$ chemical shifts were referenced to DMSO-d 6 , at $2.50 \mathrm{ppm}$ and 
$33839.52 \mathrm{ppm}$, respectively. Manual baseline-correction and integration of ${ }^{13} \mathrm{C}$ spectra were carried 339 out using Origin software.

340 Catalyst characterization. $\mathrm{NH}_{3}-\mathrm{TPD}$ measurements were conducted at a Micromeritics 341 AutoChem II Chemisorption Analyzer. $100 \mathrm{mg}$ of sample were degassed under vacuum conditions 342 while ramping the temperature to $500^{\circ} \mathrm{C}$ (heating rate $=10^{\circ} \mathrm{C} / \mathrm{min}$ ). The sample was purged with $34325 \mathrm{~mL} / \mathrm{min} \mathrm{He}$ for $60 \mathrm{~min}$, followed by cooling to $100^{\circ} \mathrm{C}$ under $\mathrm{He} .1$ vol- $\% \mathrm{NH}_{3}$ in $\mathrm{He}$ was dosed 344 over the sample for $120 \mathrm{~min}$, followed by flushing with $25 \mathrm{~mL} / \mathrm{min} \mathrm{He}$ for $60 \mathrm{~min}$. The TPD was 345 conducted at a heating rate of $5{ }^{\circ} \mathrm{C} / \mathrm{min}$ with $25 \mathrm{~mL} / \mathrm{min}$ He flowrate and the signal of desorbed $346 \mathrm{NH}_{3}$ was measured by a TCD detector.

347 A Quanatachrome AsiQ instrument was used for Ar-physisorption measurements. N2348 physisorption was conducted at a Quantachrome Novatouch apparatus. Isotherms from Ar349 physisorption were analyzed using the NLDFT model applied to the adsorption branch of the 350 isotherm. For $\mathrm{N}_{2}$ characterization, the BET method and the NLDFT model for the adsorption 351 branch were applied for characterization of the surface area and mesopore distribution, 352 respectively.

353 For XRF characterization, $0.7 \mathrm{~g}$ finely ground and dried zeolite powder is weighed accurately 354 and transferred quantitatively to a platinum crucible. $6.3 \mathrm{~g} 49.75 \%$ Lithium metaborate $/ 49.75 \%$ 355 Lithium tetraborate $/ 0.5 \%$ Lithium bromide was weighed accurately and mixed with the sample in 356 the crucible. The mixture was fused for 7 minutes at $1000{ }^{\circ} \mathrm{C}$ followed by 1 minute at $1020{ }^{\circ} \mathrm{C}$, 357 and the resulting fusion melt was poured into a $32 \mathrm{~mm}$ diameter Platinum casting dish and cooled, 358 thereby forming a lithium borate glass bead with a 9:1 lithium borate to zeolite ratio. The contents 359 of $\mathrm{Al}, \mathrm{Si}, \mathrm{Na}$ and $\mathrm{P}$ in the sample were quantified on a Supermini200 WD-XRF instrument from 360 Rigaku. The calibration of the WD-XRF instrument follows EN ISO 12677 - 2011. The 
361 measurement uncertainty of the analysis of main components is $\pm 3 \%$ relative with $95 \%$ 362 confidence.

363 Powder X-ray diffraction (XRD) measurements of zeolite samples was performed using a Huber 364 G670 X-ray diffractometer with a copper tube and a primary quartz monochromator $(\mathrm{CuK} \alpha 1$ 365 radiation, $\lambda=1.54056 \AA$ ). The diffractometer operated in transmission mode with the sample 366 placed on tape in a thin layer and placed on a rotating disc-holder and data were accumulated in 367 the range of $2 \theta=5-100^{\circ}$ for $1 \mathrm{~h}$.

\section{Results}

369 Catalyst characterization. Physicochemical properties of the parent CBV55 (freshly calcined),

370 the steamed version of it and the regenerated version obtained after multiple upgrading and 371 regeneration steps are summarized in Table 2. Results of $\mathrm{NH}_{3}-\mathrm{TPD}$ (Figure S1) indicate that the 372 strong acid sites desorbing chemisorbed $\mathrm{NH}_{3}$ at $\mathrm{T}>275^{\circ} \mathrm{C}$ amount to $0.43 \mathrm{mmol} / \mathrm{g}$ for the parent 373 zeolite. After steaming, the strong acidity decreased to $0.14 \mathrm{mmol} / \mathrm{g}$, about one third of the initial 374 value. After upgrading a total amount of fed biomass corresponding to $\mathrm{B}: \mathrm{C}=7.9$ and two 375 regeneration steps, the strong acidity further decreased to $0.07 \mathrm{mmol} / \mathrm{g}$, corresponding to $49 \%$ of 376 the strong acidity remaining after steaming. Interestingly, after additional upgrading of biomass 377 corresponding to an accumulated $\mathrm{B}: \mathrm{C}=20.1$ and two additional coke burn-offs, the acidity did not 378 reduce further. The total acidity measured by $\mathrm{NH}_{3}-\mathrm{TPD}$ after the test series (sum $\mathrm{B}: \mathrm{C}=28$, four 379 regenerations) was reduced to $\sim 80 \%$ of the value of the steamed version, which indicates that the 380 acid sites remaining after the steam pretreatment did not change much over the course of the 381 experimental series. The acidity of the zeolite at the end of the test series would correspond to a 382 theoretical molar $\mathrm{Si} / \mathrm{Al}$ ratio of 65 , indicating the extent of dealumination by the combined effect 383 of steaming and use compared to 29.5 for the parent zeolite. Since the stronger acid sites decrease 
384 more compared to the weak acid sites, it seems the stronger acid sites are more prone to hydrolysis 385 of the Si-OH-Al bond, which causes transformation of their tetrahedrally framework positions into 386 octahedrally coordinated, extra-framework positions. This agrees well with Ong et al. `s 387 observations [29] that the concentration of Lewis acid sites remained almost constant during 388 steaming of HZSM-5 while the concentration of Brønsted acid sites followed an exponential 389 decay.

390 The pore structure and surface area of a freshly calcined CBV55, a steamed CBV55 and a sample 391 which has undergone steaming, multiple upgrading experiments ( $\operatorname{sum} B: C=28$ ) and four oxidative 392 regenerations was characterized by high resolution Ar-physisorption and $\mathrm{N}_{2}$-physisorption 393 (Figure S2 and S3). Reduced $\mathrm{N}_{2}$ uptake at $\mathrm{p} / \mathrm{p}_{0}<0.1\left(18 \%\right.$ lower) and $\mathrm{p} / \mathrm{p}_{0}>0.9$ is observed 394 comparing the used CBV55 $\left(\mathrm{st}^{-} \mathrm{u}^{7}-\mathrm{r}^{4}\right)$ with the fresh CBV55. The Ar-physisorption indicates a BET 395 surface area reduction from 485 to $432 \mathrm{~m}^{2} / \mathrm{g}$, while $\mathrm{N}_{2}$-physisorption indicates an even larger 396 reduction in BET surface area from 468 to $385 \mathrm{~m}^{2} / \mathrm{g}$. A larger reduction in surface area is observed 397 after steaming (e.g. by partial collapse of instable framework). The reduction in surface area is 398 deemed unlikely to have a pronounced change on the deoxygenation activity of the catalyst, which 399 may rather be attributed to the zeolite's loss of strong acid sites after the steam treatment.

400 A zeolite sample was analyzed by XRF after the test series to investigate any transfer of alkali 401 metals. No accumulation of potassium was detected, which shows that the hot gas filtration at 350 $402{ }^{\circ} \mathrm{C}$ was effective in retaining potassium.

403 A comparison of the obtained XRD patterns is provided in Figure S4, indicating orthorhombic 404 (PNMA) symmetry. The similarity of the XRD patterns between the parent CBV55 and after the 405 steaming and repeated reaction/regeneration cycles indicates that the characteristic MFI 406 framework of ZSM-5 was retained. An estimate of the relative crystallinity of the steamed and 
407 used samples was obtained by measuring the intensity of the diffraction signal of the (051) peak 408 and comparing it to that of the reference un-steamed sample [29]. After baseline subtraction, this 409 method suggests that the relative crystallinity was reduced to $98.7 \%$ after steaming and further to $41094.3 \%$ after the repeated reaction/regeneration cycles. Our characterization results agree well with 411 others who have considered the effect of steaming on ZSM-5 [29] and who studied the deactivation 412 of HZSM-5 zeolite in CFP after repeated reaction-regeneration cycles $[42,43]$. We note a peak 413 splitting of the XRD peak at $2 \theta=24.4^{\circ}$ after the steam treatment, which is tentatively attributed a 414 change in unit cell volume. Knöll et al. [44] found that the unit cell volume of ZSM-5 decreased 415 with increasing steaming time and therefore correlated well with a decrease in the zeolite`s acidity 416 and propylene yield.

417 Table 2. Physical \& chemical characterization for the parent CBV55 (freshly calcined), after 418 steaming (CBV55-st) and after additional upgrading/regeneration steps (CBV55-st-u $\left.{ }^{7}-\mathrm{r}^{4}\right)$.

\begin{tabular}{|l|c|c|c|c|c|c|c|}
\hline & Surface area & $\begin{array}{c}\text { Total pore } \\
\text { volume at } \\
\mathrm{p} / \mathrm{p}_{0}=0.99\end{array}$ & $\begin{array}{c}\text { Micropore } \\
\text { volume }^{\mathrm{b}}\end{array}$ & $\begin{array}{c}\text { Mesopore } \\
\text { volume }^{\mathrm{a}}\end{array}$ & Acidity $^{\mathrm{c}}$ & $\begin{array}{c}\text { Strong } \\
\mathrm{acidity}^{\mathrm{c}} \\
\text { desorbing }> \\
275^{\circ} \mathrm{C}\end{array}$ & $\begin{array}{c}\text { Molar } \\
\mathrm{Si} / \mathrm{Al} \\
\text { ratio }^{\mathrm{d}}\end{array}$ \\
\hline CBV55 & 468 & 0.31 & 0.22 & 0.12 & 0.65 & 0.43 & 29.5 \\
\hline CBV55-st & 399 & 0.29 & 0.17 & 0.13 & 0.36 & 0.14 & 27.8 \\
\hline CBV55-st-u & {$[\mathrm{cc} / \mathrm{g}]$} & {$[\mathrm{cc} / \mathrm{g}]$} & {$[\mathrm{cc} / \mathrm{g}]$} & {$[\mathrm{mmol} / \mathrm{g}]$} & {$[\mathrm{mmol} / \mathrm{g}]$} & - \\
\hline
\end{tabular}

$419{ }^{a}$ determined by $\mathrm{N}_{2}$ physisorption; ${ }^{\mathrm{b}}$ determined by Ar physisorption; ${ }^{\mathrm{c}}$ determined by $\mathrm{NH}_{3}-\mathrm{TPD}$; 420 determined by XRF

421 Product distribution. A mass balance closure of $95 \%$ was obtained for the SiC case. The mass 422 balance closure obtained for the initial upgrading $(\mathrm{B}: \mathrm{C}=0-1.7)$ over $151 \mathrm{~g}$ CBV55-st was $101 \%$, 423 and the mass balance for the four successive upgrading steps up to $\mathrm{B}: \mathrm{C}=6.2$ including the final 424 coke burn-off over CBV55-st-u-r amounts to 94\%. For the investigation of B:C = 6.5 and 12.9 
425 using only $15 \mathrm{~g}$ catalyst the mass balance closure was $87-90 \%$. Losses are related to residues

426 inside the system and minor volatilization of compounds from the collected liquids with low vapor

427 pressure prior to their gravimetric determination. An empty reactor test at $500^{\circ} \mathrm{C}$ with straw 428 feedstock yielded 36 wt- $\%$ organic liquid, which was reduced to $28 \%$ (on daf basis) when the 429 reactor was filled with $60 \mathrm{ml} \mathrm{SiC}$ at $500{ }^{\circ} \mathrm{C}$. Using pine wood as feedstock and passing the vapors 430 over $\mathrm{SiC}$ under otherwise same conditions resulted in $16.2 \%$ char, $15.8 \%$ reaction water, $43 \%$ 431 organic liquid and $14.7 \%$ gas. The differences in yield using wood as feedstock can be attributed 432 to its lower ash content (0.2 wt-\%) compared to wheat straw (5.9 wt-\%).

433 A comparison of $\mathrm{CO}$ and $\mathrm{CO}_{2}$ evolution during the regeneration of a coked catalyst $(151 \mathrm{~g})$ after $434 \mathrm{~B}: \mathrm{C}=0-1.7$ and $\mathrm{B}: \mathrm{C}=0-6.2$ and for $15 \mathrm{~g}$ coked catalyst after $\mathrm{B}: \mathrm{C}=0-6.5$ and $\mathrm{B}: \mathrm{C}=0-12.9$ 435 can be found in Figure S5. An exemplary temperature profile of the catalyst bed during upgrading 436 to $\mathrm{B}: \mathrm{C}=12.9$ over $15 \mathrm{~g}$ catalyst measured at the bed inlet, middle and outlet can be found in Figure 437 S6. In Figure 1, the product distribution (except coke) obtained from each of the successive 438 upgrading experiments is shown. It should be noted that between each upgrading step the unit is 439 purged with nitrogen, cooled down and reheated for the next upgrading. In [26] it was observed 440 that the signals of olefins and aromatics increase up to a $\mathrm{B}: \mathrm{C}=0.2$ when upgrading pine pyrolysis 441 vapors over HZSM-5. This suggests an induction period to filling up accessible micropores with 442 reactants and establishing the product formation according to the "hydrocarbon pool" mechanism 443 observed for the methanol-to-olefin process [45]. Since the char separation occurred prior to the 444 catalyst bed, the char yield was not influenced by the catalyst operating conditions. The yield of $445 \mathrm{C}_{2}$ and $\mathrm{C}_{3}$ olefins decreased with increased amount of biomass fed to the system. Likewise, a 446 decreasing trend in the amount of reaction water and an increased yield of organic liquid was 447 observed, consistent with a lower degree of protolytic cracking. However, even for B:C = 3.6 - 6.2 
448 the oil yield was $40 \%$ lower relative to the non-catalytic (SiC) reference case. It is noted that after 449 a first regeneration of the catalyst, less gas, water, and oil were formed at B:C $=0-1.1$ compared 450 to $\mathrm{B}: \mathrm{C}=0-1.7$ prior to regeneration, which may be attributed to higher losses to coke since the 451 experiment was stopped at a lower B:C ratio. In order to obtain an overall product distribution 452 including the coke yields, the results obtained for the upgrading experiments over CBV55-st and 453 the four successive B:C conversions over the regenerated catalyst were averaged based on their 454 weight yields (Figure 2). The cumulative amount of biomass (daf) converted over these four 455 experiments corresponds to $\mathrm{B}: \mathrm{C}=6.2$. The coke amount determined by coke burn-off at the end 456 of these four experiments was $11.2 \mathrm{wt}-\%$ of the coked catalyst bed. This corresponds to $4.2 \%$ of 457 the carbon introduced by the biomass feed during the four successive upgrading steps. Figure 2 458 also includes the product distribution obtained from operating at $\mathrm{B}: \mathrm{C}=0-12.9$ and $\mathrm{B}: \mathrm{C}=0-6.5$ 459 over $15 \mathrm{~g}$ catalyst and illustrates the increase in oil yield at higher B:C ratios. A lower degree of 460 conversion can be expected at the reduced amount of catalyst loaded, which explains the lower 461 coke yield of only $1.3 \mathrm{wt}-\%$ per daf feed for $\mathrm{B}: \mathrm{C}=6.5$, while the additional vapor contact time 462 when 10 times more catalyst was loaded $(\mathrm{B}: \mathrm{C}=6.2)$ resulted in a higher chance of polymerization 463 of aromatic products and thus, elevated coke yields (4.1 wt-\% per daf feed). We note that at B:C $464=12.9$ the yield of reaction water with $15 \mathrm{~g}$ catalyst loaded drops below values obtained for the $465 \mathrm{SiC}$ reference bed. Since about twice the volume of SiC was filled compared to $15 \mathrm{~g} \mathrm{CBV55,}$ 466 additional thermal cracking is possibly the reason for the increased water yield [46]. The $\mathrm{C}_{2}$ and $467 \mathrm{C}_{3}$ olefin yield $\left(\mathrm{C}_{2 / 3}=\right)$ decreased with increasing catalyst deactivation, but also the yield of $\mathrm{CO}$, $468 \mathrm{CO}_{2}$, and $\mathrm{C}_{1}-\mathrm{C}_{3}$ hydrocarbons decreased. Little change was observed for the hydrogen yield, 469 accounting to $0.52 \mathrm{wt}-\%(\sim 2$ vol- $\%$ in carrier free NCG) for both low and high $\mathrm{B}: \mathrm{C}$ ratios. 470 Naturally, the coke yields are higher during the initially very active phase of the catalyst and the 
471 rate of coke build-up gradually decreased with time on stream [11]. It is desirable to limit coke

472 formation in order to minimize catalyst deactivation. With higher amounts of biomass fed over the

473 catalyst, the amount of $\mathrm{C}$ in coke per biomass fed is reduced since more acid sites become 474 inaccessible or deactivated. Assuming a carbon density of $2 \mathrm{~g} / \mathrm{cc}$ and taking the total pore volume 475 of microporous CBV55 into account $\left(0.439 \mathrm{cc} / \mathrm{g}\right.$ as determined by $\mathrm{N}_{2}$ physisorption at $\left.\mathrm{p} / \mathrm{p}_{0}=0.99\right)$, 476 it can be estimated that after upgrading to $\mathrm{B}: \mathrm{C}=6.2$, about $14 \%$ of the pores were filled with coke.

477 While this may appear low, for a purely microporous ZSM-5 a larger extent of micropore volume 478 may become inaccessible once the pore mouth entries are capped with coke. Coke formation on 479 the external surface (mesopores) was observed by Mukarakate et al. [26] and attributed to 480 condensation reactions of unconverted lignin primary products and polymerization of aromatic 481 hydrocarbons.

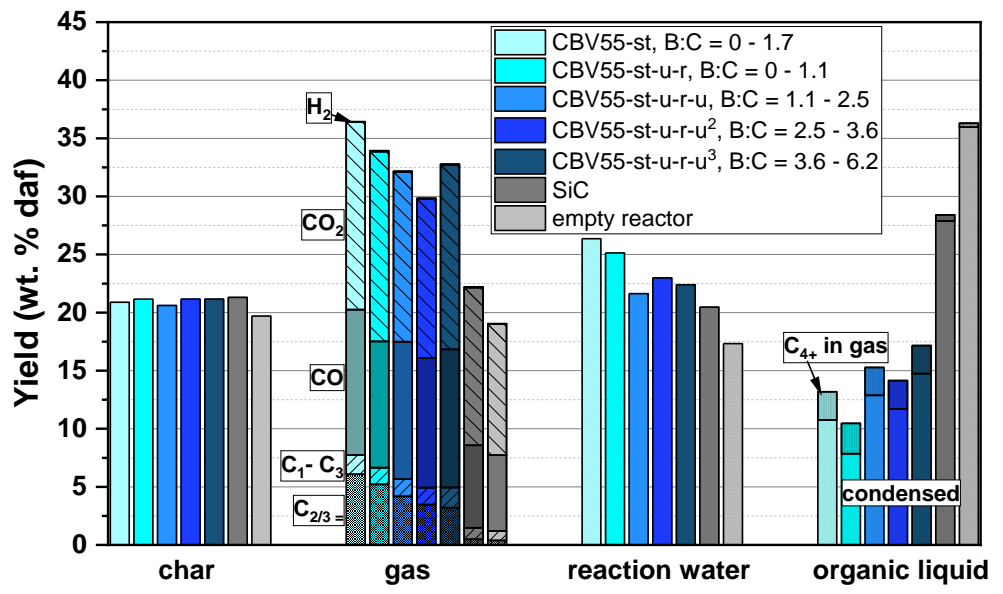

483 Figure 1. Product distribution obtained for $151 \mathrm{~g} \mathrm{CBV55-st} \mathrm{for} \mathrm{B}: \mathrm{C}=0-1.7$ and successive 484 biomass (straw) feeding over the regenerated catalyst CBV55-st-u-r in comparison to a non485 catalytic $\mathrm{SiC}$ bed and an empty reactor. Coke is not shown here since it was not determined in the 486 successive upgrading experiments. 


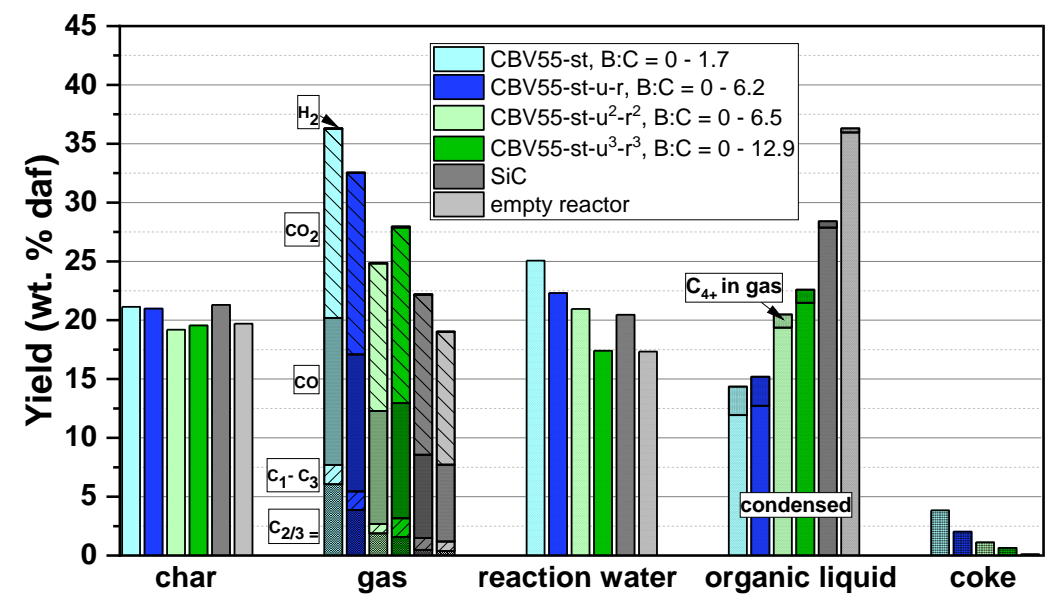

Figure 2. Product distribution obtained from upgrading of straw pyrolysis vapors over steamed

489 CBV55 at increasing B:C ratio. Blue and green bars refer to results obtained using $151 \mathrm{~g}$ and $15 \mathrm{~g}$ 490 catalyst, respectively. Product distribution obtained with SiC bed and empty reactor shown for 491 reference. Conditions: $T_{\text {catalyst }}=500{ }^{\circ} \mathrm{C}, \mathrm{WHSV}=0.64$ g biomass $/\left(\mathrm{g}_{\text {catalyst }} \cdot \mathrm{h}\right), 8 \mathrm{Nl} / \mathrm{min} \mathrm{N}_{2}$ flow .

492 Energy and carbon balance. For each experiment, the resulting heating value (HHV) for the 493 sum of oil fractions $\left(4^{\circ} \mathrm{C} \mathrm{OF}+\mathrm{ESP} \mathrm{OF}+-60^{\circ} \mathrm{C} \mathrm{OF}\right)$ was estimated based on the HHV and yield 494 of the individual fraction. A detailed listing of the obtained elemental composition and calculated 495 heating values for both oil and aqueous fractions can be found in the supporting information in 496 Table S2 - S10. As can be seen in Table 3, at low B:C ratio a considerable enhancement of the 497 oil quality is achieved by production of oil with a HHV of $38 \mathrm{MJ} / \mathrm{kg}$ compared to the non-catalytic 498 reference case with $\sim 29 \mathrm{MJ} / \mathrm{kg}$. Notably, the thermal cracking itself already leads to an energy 499 densification in the liquid product compared to the straw feedstock with $\sim 19 \mathrm{MJ} / \mathrm{kg}$. Energy 500 balance closures were in the range of $77-93 \%$ within this test series. The energy content of the 501 condensed organics is distributed between the condensed oil and aqueous phase (see Figure S7).

502 With increasing catalyst deactivation, the energy losses to non-condensable gases decreases. While 503 the HHV for oils obtained at low B:C ratio of 1.7 and 1.1 are higher by about $30 \%$ relative to the 
$504 \mathrm{SiC}$ case, the energy recovery into the OL, i.e. the sum of condensed OF and WF, is lower 505 compared to the $\mathrm{OL}$ obtained from $\mathrm{SiC}$ due to the higher losses to coke and $\mathrm{CO}_{\mathrm{x}}$ when using a 506 catalyst. Using $151 \mathrm{~g}$ of catalyst $(\mathrm{B}: \mathrm{C}=0-6.2)$ compared to using only $15 \mathrm{~g}(\mathrm{~B}: \mathrm{C}=0-6.5)$ 507 improved the liquid properties, but resulted in higher energy losses to gas and coke. The carbon 508 product distribution (Figure 3) shows that the carbon yield into the gas phase decreased with 509 increasing B:C ratio, while the carbon recovered into the oil fraction increased and a slight decrease 510 in the $\mathrm{C}_{4+}$ products is observed. Less than $2 \%$ of biogenic carbon was lost into the phase separated 511 aqueous product stream obtained from the successive vapor upgrading up to $\mathrm{B}: \mathrm{C}=6.2$ using 151 $512 \mathrm{~g}$ catalyst. In contrast, using a reduced amount of $15 \mathrm{~g}$ catalyst resulted in carbon losses of 4.9 and $5135.5 \%$ for $\mathrm{B}: \mathrm{C}=0-6.5$ and $\mathrm{B}: \mathrm{C}=0-12.9$, respectively. The highest amount of $10.3 \%$ carbon was 514 lost into the aqueous phase for the $\mathrm{SiC}$ reference case. In a recent work by Starace et al. [47] it was 515 reviewed that most groups working with CFP report that a significant amount of carbon (3- 14 516 wt- $\%$ of the original biomass carbon) is retained in the aqueous stream. Different process 517 conditions and biomass types could account for the differences.

518 Table 3. Comparison of the oil yields and oxygen content, their higher heating values (calculated 519 based on elemental composition) and their energy yields obtained for empty reactor bed, $\mathrm{SiC}$ and 520 increasing $\mathrm{B}: \mathrm{C}$ ratios using $15 \mathrm{~g}$ and $151 \mathrm{~g}$ CBV55-st.

\begin{tabular}{|c|c|c|c|c|c|}
\hline $\begin{array}{c}\text { Amount } \\
\text { of } \\
\text { catalyst }\end{array}$ & & $\begin{array}{l}\text { Oil yield } \\
\text { of daf } \\
\text { biomass } \\
\text { [wt-\%daf] }\end{array}$ & $\begin{array}{c}\text { wt-\% } \\
\text { oxygen } \\
\text { (dry) in } \\
\text { sum OF }\end{array}$ & $\begin{array}{c}\text { Sum OF } \\
\mathrm{HHV}_{\mathrm{db}} \\
{[\mathrm{MJ} / \mathrm{kg}]}\end{array}$ & $\begin{array}{l}\text { Energy } \\
\text { yield in } \\
\text { sum OF }\end{array}$ \\
\hline - & empty reactor & 24.6 & 26.5 & 27.7 & $35.1 \%$ \\
\hline $95 \mathrm{~g}$ & thermal cracking $(\mathrm{SiC})$ & 19.4 & 21.5 & 29.2 & $30.4 \%$ \\
\hline \multirow{3}{*}{$151 \mathrm{~g}$} & CBV55-st, B:C = $0-1.7$ & 9.9 & 5.6 & 37.7 & $19.3 \%$ \\
\hline & CBV55-st-u-r, B:C $=0-1.1$ & 7.2 & 5.7 & 37.9 & $14.0 \%$ \\
\hline & CBV55-st-u-r-u, B:C $=1.1-2.5$ & 11.6 & 9.5 & 35.7 & $21.4 \%$ \\
\hline
\end{tabular}



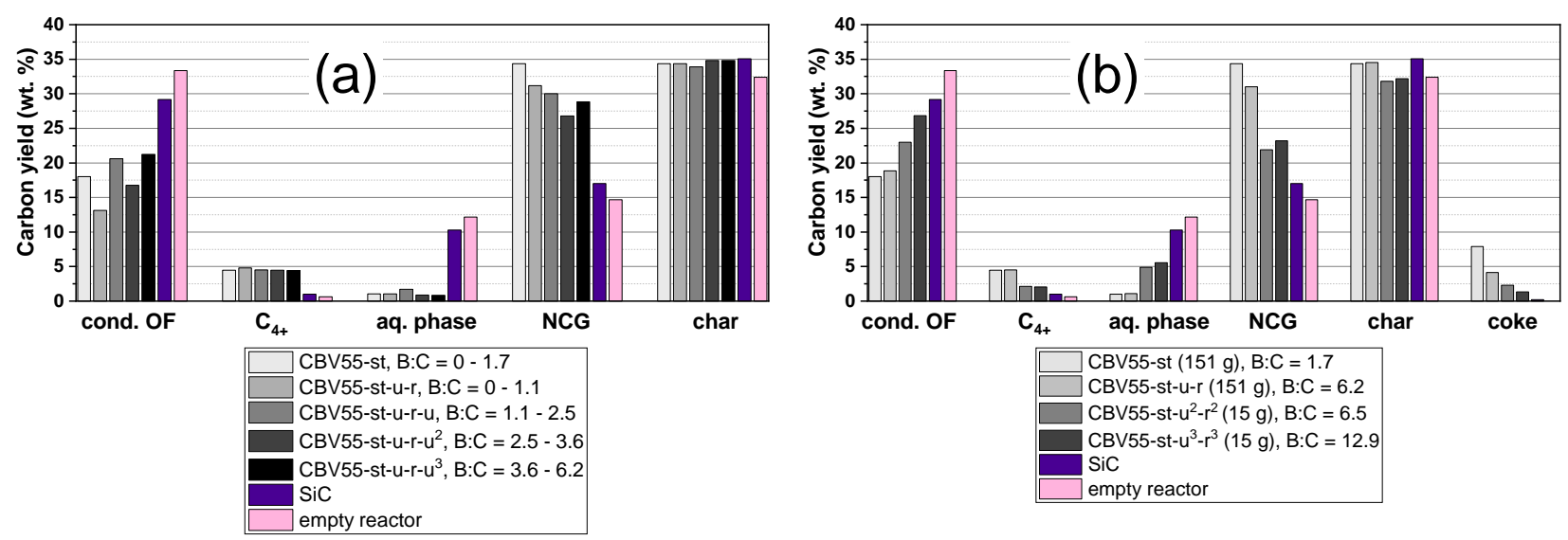

522 Figure 3. Product carbon distributions from empty reactor bed and upgrading straw pyrolysis 523 vapors over $\mathrm{SiC}$ and CBV55-st. In (a), the carbon distribution (except coke) obtained from step524 wise feeding of biomass up to $\mathrm{B}: \mathrm{C}=6.2$ is shown using $151 \mathrm{~g}$ catalyst. In (b), the carbon product 525 distributions including coke obtained for both $151 \mathrm{~g}$ and $15 \mathrm{~g}$ catalyst is compared for increasing $526 \mathrm{~B}: \mathrm{C}$ ratios and to the non-catalytic reference case $(\mathrm{SiC})$. Condensed $\mathrm{OF}$ and aqueous phase refer 527 to sum OF and sum WF, respectively.

Process optimization. The catalyst performance in terms of recovered oil fraction and reduction

529 in oxygen content with respect to thermal cracking over a $\mathrm{SiC}$ bed is suitably compared by plotting 530 the extent of deoxygenation (relative to thermal cracking) against the carbon yield. In a 531 conservative comparison, the (usually oxygenated) organics present in the WF are neglected.

532 Taking the organics dissolved into the WF into account would increase the carbon yield, but may 533 also reduce the overall degree of deoxygenation. The gas phase contribution of olefins and $\mathrm{C}_{4+}$ are 534 not taken into account for calculation of the sum OF carbon yield, even though these valuable 
535 deoxygenated compounds may be recovered using appropriate recovery systems. For the test536 series of incremental biomass conversion after the first regeneration step, the oxygen content is 537 calculated which would result in the mixture of collected oil fractions up to the B:C ratio at which 538 the experiment was stopped. This way a better understanding of the cumulative oil properties is 539 obtained. Figure 4 compares the extent of deoxygenation for the sum of OF with the oils carbon 540 yield. It is apparent that a reduced oxygen content can only be achieved at the expense of a reduced 541 carbon yield. According to Venderbosch [48], the properties of the accumulated oils obtained in 542 the lower B:C range up to 6.2 would be classified as region II corresponding to severe 543 deoxygenation at the expense of carbon. The extended B:C range $0-12.9$ results in mild 544 deoxygenation corresponding to region I in Figure 4 close to the non-catalytic reference case. 545 However, when comparing the carbon yield and the extent of deoxygenation for the range $\mathrm{B}: \mathrm{C}=$ $5463.6-6.2$, it appears that only mild deoxygenation takes place over the partly deactivated catalyst.

547 One could consider that the optimal case is to reduce the oxygen content only to an extent 548 necessary to allow stable operation of a hydrodeoxygenation process or successful co-feeding at a 549 refinery`s FCC unit. For example, it may be favorable to operate up to a B:C ratio of $\sim 4$ in order 550 to obtain oils with $\sim 10$ wt- $\%$ oxygen at $\sim 56 \%$ relative organics yield (incl. $\mathrm{C}_{4+}$ ) compared to a 551 non-catalytic reference. 


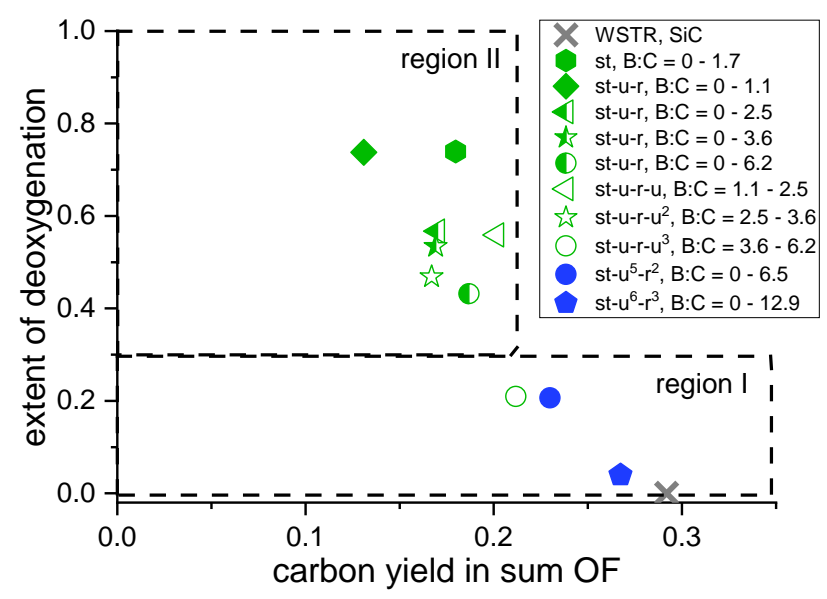

553

554 Figure 4. Correlation of the relative extent of deoxygenation (to the SiC case, 21.5 wt- $\%$ oxygen)

555 with the carbon yield for the sum of oil fractions of each run. Green and blue symbols refer to oil 556 product obtained using $151 \mathrm{~g}$ and $15 \mathrm{~g}$ catalyst, respectively. Filled symbols correspond to runs 557 starting from $\mathrm{B}: \mathrm{C}=0$ to the indicated $\mathrm{B}: \mathrm{C}$ value, whereas open symbols indicate runs starting from 558 a partly coked CBV55-st. Half-filled symbols represent calculations of the carbon yield and 559 oxygen content based on the yield and properties of the oils obtained from the consecutive runs 560 without regeneration for $151 \mathrm{~g} \mathrm{CBV55-st-u-r} \mathrm{up} \mathrm{to} \mathrm{B:C}=6.2$ The regions I and II indicate mild 561 and severe deoxygenation, respectively [48].

562 Oil characterization. Determination of the total acid number was conducted according to 563 ASTM D 664 by potentiometric determination of both oil and aqueous fractions. The acidity of 564 both the oil (sum OF) and aqueous fractions (sum WF) is summarized in Table 4. For the oil 565 fractions, a TAN content of $52.3 \mathrm{mg} \mathrm{KOH} / \mathrm{g}$ resulted for the $\mathrm{SiC}$ oil, while at $\mathrm{B}: \mathrm{C}=0-1.1$ and $566 \mathrm{~B}: \mathrm{C}=3.6-6.2$ over $151 \mathrm{~g}$ catalyst the sum of OF had a TAN of 6.4 and $14.3 \mathrm{mg} \mathrm{KOH} / \mathrm{g}$, 567 respectively. Since the non-catalytically obtained oil contained more moisture, the acids may 568 dissolve into this fraction to a higher extent compared to the upgraded oils. In accordance with the 569 higher acidity of the oil fractions at increasing B:C ratio, it is found that the TAN for the sum of 
570 WFs also increased towards higher B:C ratios. A clear jump in TAN content of both oil and 571 aqueous fractions was observed when only $15 \mathrm{~g}$ of catalyst were used, indicating less efficient 572 vapor upgrading. Interestingly, the TAN content of products obtained from $\mathrm{B}: \mathrm{C}=0-12.9$ 573 remained similar as for $\mathrm{B}: \mathrm{C}=0-6.5$. This shows that the contact of the reactive vapors with the 574 coked HZSM-5 still reduced the acidity. For the sum OF obtained during B:C $=0-12.9$, the TAN 575 content was less than $50 \%$ of the non-catalytic reference. It should be noted that the acidity for the 576 non-catalytic derived straw oils is lower than for wood derived oils. The TAN content of the wood 577 derived sum of OF and sum of WF of a reference experiment over a SiC bed amounted to 60.8 and $578 \quad 66.5 \mathrm{mg} \mathrm{KOH} / \mathrm{g}$, respectively.

579 Determination of the sulfur content for the sum of OF obtained from SiC, and oils obtained over 580 the freshly regenerated zeolite $(\mathrm{B}: \mathrm{C}=0-1.1)$ and the coked zeolite $(\mathrm{B}: \mathrm{C}=3.6-6.2)$ was measured 581 to $0.07,0.29$ and $0.1 \mathrm{wt}-\%$, respectively. The enhanced sulfur content at low B:C ratio (for the 582 most deoxygenated produced) may be attributed to the production of alkylthiophenes from $\mathrm{H}_{2} \mathrm{~S}$ 583 and olefins or diolefins, which correlates with the enhanced yield of olefins at low B:C ratio [49].

584 Table 4 - TAN values for the sum of oil fractions and aqueous fractions obtained for the SiC case, 585 and over CBV55-st-u-r (B:C=0 - 1.1 and B:C = 3.6 - 6.2).

\begin{tabular}{|c|c|c|c|c|c|c|c|c|c|c|}
\hline & \multicolumn{2}{|c|}{$\mathrm{SiC}$} & \multicolumn{2}{|c|}{$\begin{array}{c}\mathrm{B}: \mathrm{C}=0-1.1 \\
\quad(151 \mathrm{~g})\end{array}$} & \multicolumn{2}{|c|}{$\begin{array}{c}\mathrm{B}: \mathrm{C}=3.6-6.2 \\
(151 \mathrm{~g})\end{array}$} & \multicolumn{2}{|c|}{$\begin{array}{c}\mathrm{B}: \mathrm{C}=0-6.5 \\
\quad(15 \mathrm{~g})\end{array}$} & \multicolumn{2}{|c|}{$\begin{array}{c}\mathrm{B}: \mathrm{C}=0-12.9 \\
\quad(15 \mathrm{~g})\end{array}$} \\
\hline & sum OF & sum WF & sum OF & sum WF & sum $\mathrm{OF}$ & sum WF & sum OF & sum WF & sum OF & sum WF \\
\hline $\begin{array}{l}\text { Fraction of } \\
\text { collected liquid } \\
\text { product }\end{array}$ & $37.9 \%$ & $62.1 \%$ & $17.4 \%$ & $82.6 \%$ & $29.9 \%$ & $70.1 \%$ & $30.7 \%$ & $69.3 \%$ & $38.7 \%$ & $61.3 \%$ \\
\hline $\begin{array}{l}\text { TAN } \\
{[\mathrm{mg} \mathrm{KOH} / \mathrm{g}]}\end{array}$ & 52.3 & 60.3 & 6.4 & 2.7 & 14.3 & 4.6 & 26.0 & 37.7 & 22.8 & 37.6 \\
\hline $\begin{array}{l}\text { TAN of total liquid } \\
{[\mathrm{mg} \mathrm{KOH} / \mathrm{g}]}\end{array}$ & \multicolumn{2}{|c|}{57.3} & \multicolumn{2}{|c|}{3.4} & \multicolumn{2}{|c|}{5.6} & \multicolumn{2}{|c|}{34.1} & \multicolumn{2}{|c|}{31.9} \\
\hline
\end{tabular}


587 The Van Krevelen plot (Figure 5) illustrates the quality of the obtained liquids by plotting the 588 molar $\mathrm{H}: \mathrm{C}$ against the $\mathrm{O}: \mathrm{C}$ ratio of the sum of the oil fractions from each upgrading step. The 589 organic liquid lost into the aqueous stream was not included in this comparison due to the 590 uncertainty related to determining the oxygen content of the small amount of organics dissolved 591 in the highly aqueous fractions. A clear reduction in the oxygen content of the oil fractions was 592 observed for the first upgrading step over CBV55-st in comparison to the liquid product obtained 593 for passing the vapors over the $\mathrm{SiC}$ bed. However, it is apparent that oxygen was expelled to a 594 high extent in the form of water and therefore hydrogen was lost. After the first upgrading cycle 595 and regeneration of the catalyst, a similar degree of deoxygenation was obtained at a B:C ratio of 5961.1 compared to 1.7 for the initial upgrading step, however at a slightly reduced $\mathrm{H} / \mathrm{C}$ ratio. Moving 597 towards $\mathrm{H} / \mathrm{C}$ of 1 at $\mathrm{O} / \mathrm{C}$ of zero indicates the formation of aromatics. The incremental feeding of 598 vapors from $\mathrm{B}: \mathrm{C}=1.1$ to 6.2 without regenerating the catalyst decreased the extent of 599 deoxygenation with increasing $\mathrm{H} / \mathrm{C}$ ratio. When one-tenth of catalyst was used during $\mathrm{B}: \mathrm{C}=0-$ 6006.5 , a higher molar $\mathrm{H} / \mathrm{C}$ and $\mathrm{O} / \mathrm{C}$ ratio resulted compared to using $151 \mathrm{~g}$ catalyst, which can be 601 attributed to a lower extent of conversion of pyrolysis vapors at shorter catalyst contact time. For $602 \mathrm{~B}: \mathrm{C}=0-12.9$ the molar $\mathrm{O} / \mathrm{C}$ ratio further increased along with the $\mathrm{H} / \mathrm{C}$ ratio, indicating that mild 603 deoxygenation preserved a higher $\mathrm{H} / \mathrm{C}$ ratio. 
604

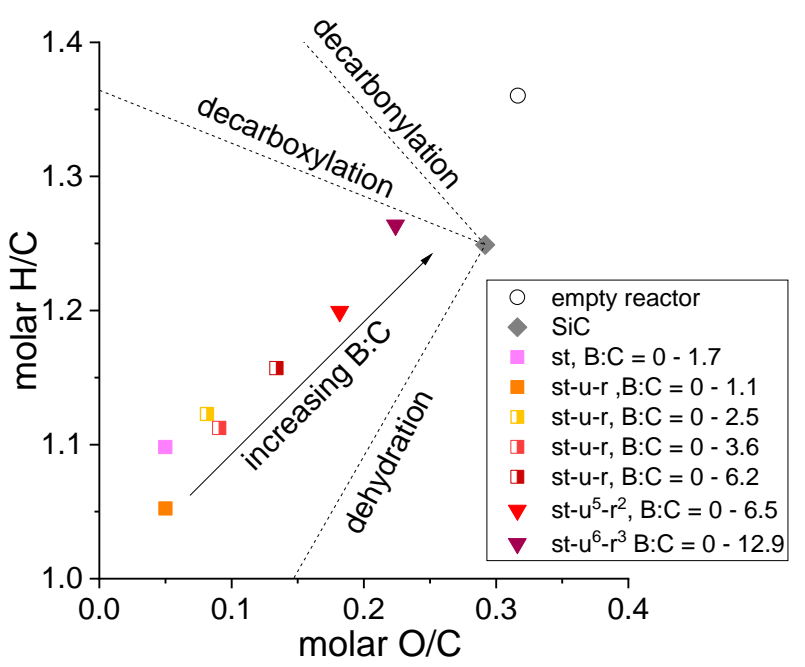

605 Figure 5. Molar $\mathrm{H} / \mathrm{C}$ vs. O/C ratio for the sum OFs obtained for increasing amounts of straw 606 pyrolysis vapors fed over CBV55-st $\left(500{ }^{\circ} \mathrm{C}\right)$. SiC bed and empty reactor $\left(500{ }^{\circ} \mathrm{C}\right)$ shown as 607 reference. Square symbols relate to results obtained with $151 \mathrm{~g}$ catalyst while triangles refers to 608 oils obtained using only $15 \mathrm{~g}$ of CBV55-st. Half-filled symbols constitute calculations properties 609 for the mixture of oils obtained from successive feeding of biomass (see Scheme 2). 610 Deoxygenation pathways are indicated by dashed lines.

611 Based on detailed product analysis of all five condensation fractions by GC-MS/FID, the yields of 612 over 200 quantified components are grouped into monoaromatics, diaromatics, polycyclic 613 aromatics, aliphatic hydrocarbons, phenols, methoxy-phenols, furans/furfural, ester, alcohols, 614 ethers aldehydes and ketones. A detailed list of components of which each group is comprised of 615 can be found in Table S11 - Table S24. The grouping was conducted on basis of oxygen 616 functionalities, thus aromatic molecules containing a single oxygen functionality were grouped as 617 oxygenate and not as aromatic. A comparison of detectable groups from quantitative GC-FID 618 analysis for the total organic liquid products is shown in Figure 6. Oxygenated components present 619 at yields less than $0.1 \mathrm{wt} \%$ were lumped into one category "Lump of Oxygenates $<0.1 \mathrm{wt} \%$ ". The 620 results were obtained by analyzing both the aqueous fractions and oil fractions separately, i.e. for 
621 each experiment the five different liquid products were analyzed. The highest yield of aromatics

622 and phenols is obtained at $\mathrm{B}: \mathrm{C}=0-1.7$ over steamed CBV55. After regeneration, a lower

623 aromatics yield is obtained at $\mathrm{B}: \mathrm{C}=0-1.1$, which may result both from the lower $\mathrm{B}: \mathrm{C}$ range and

624 thus higher losses to coke and gas, but also the zeolite`s acidity may have been slightly reduced

625 by the first upgrading and regeneration cycle. Continued feeding of biomass from $\mathrm{B}: \mathrm{C}=1.1-2.5$

626 and $\mathrm{B}: \mathrm{C}=2.5-3.6$ decreases the yield of monoaromatics over the coked catalyst considerably,

627 while additional feeding of biomass beyond $\mathrm{B}: \mathrm{C}=3.6$ reduces the aromatics yields only slightly.

628 It is apparent that the increase in oil yield as a result of catalyst deactivation cannot compensate

629 the loss in aromatics selectivity. Phenols may form from cracking of guaiacol-like molecules,

630 which would indicate that less cracking reactions of these molecules occur with increased coke

631 occluding and poisoning acid sites. When upgrading pine pyrolysis vapors over HZSM-5, it was

632 shown by Mukarakate et al. [26] that the intermediate species furans, phenol and cresols reached

633 a maximum at $\mathrm{B}: \mathrm{C} \sim 0.8$. These intermediates will desorb at an increased rate out of the pores once

634 the active sites in the catalyst became increasingly poisoned by coke. In this study, the yield of

635 alcohols and ketones increased with higher B:C. The incomplete conversion of these reactive

636 compounds indicates severe catalyst deactivation. It should be kept in mind that these observations

637 are valid only for the detectable GC range. The identified components only account for a certain

638 fraction of the total organic liquid. The oil fraction obtained from the $-60{ }^{\circ} \mathrm{C}$ condensation stage is

639 well suited for analysis with the column configuration, which allows quantifying up to $\sim 85 \%$ of

640 this fraction. More $-60^{\circ} \mathrm{C}$ OF product is collected at lower B:C ratios, while increasing B:C ratios

641 increase the relative yields of oils collected at the ESP and $4{ }^{\circ} \mathrm{C}$ stage. For these fractions, only

642 about $20 \%$ can be quantified with the applied chromatographic method. As a result, the range of

643 GC-identifiable organics decreases with increasing catalyst deactivation (Table S25). While 
$64464.4 \%$ could be identified for the sum of OF obtained within B:C $=0-1.1$, only $27.3 \%$ were 645 identified for the sum of OF obtained from B:C $=3.6-6.2$, and only $11.6 \%$ were identified in the $646 \mathrm{SiC}$ case.

647 SEC was conducted for the $\mathrm{SiC}$ oil and oils obtained using CBV55-st for operation at B:C $=0-$ 6481.1 and B:C $=3.6-6.2$ (Figure S8). The SEC chromatogram from the SiC oil can be de649 convoluted into seven contributions. The majority of the molecular weight distribution appears to 650 be located below $1000 \mathrm{Da}$, which is quite low compared to reported weight distributions extending 651 up to $10000 \mathrm{Da}$ for non-catalytic wood derived oils [50]. As for non-catalytic bio-oil obtained from 652 straw fast pyrolysis, MW distributions up to 3000 Da have been reported by Trinh et al. [51]. The 653 lower molecular weight of our thermal reference oils can be partly attributed to the additional 654 cracking effect upon contact of the vapors with fine char containing high concentration of the 655 biomass indigenous alkaline ashes (especially K) at the hot gas filtration surface and partly to the 656 effect of the $\mathrm{SiC}$ bed. A loss of up to $30 \mathrm{wt} \%$ of the liquid product yield has been reported in 657 literature by HGF due to cracking reactions occurring upon contact of the vapors with the alkali 658 metals in char, which produces a narrower molecular weight distribution $[23,46,52,53]$. For oil 659 product obtained at $\mathrm{B}: \mathrm{C}=0-1.1$, it can be noted that a very intense refractive index (RI) response 660 results at lower MW, indicating a more narrow distribution in molecular size in the range of 661 toluene. This agrees well with the high aromatic character determined by GC-MS/FID, ${ }^{1} \mathrm{H}$ NMR 662 and ${ }^{13} \mathrm{C}$ NMR, and the improved re-evaporation behavior. For oil obtained over the coked catalyst 663 (B:C=3.6-6.2), the shoulders attributed to the higher MW contributions started to appear in the 664 chromatogram, with exception of the two highest contributions eluting at $7.9 \mathrm{ml}$ and $8.45 \mathrm{ml}$. For $665 \mathrm{~B}: \mathrm{C}=3.6-6.2$, the contribution eluting in proximity to the toluene reference is significantly 666 reduced compared to the severely deoxygenated oil, yet still enhanced compared to the $\mathrm{SiC}$ 
667 reference oil. The high intensity of the RI response for oil obtained at B:C $=0-1.1$ could indicate

668 absorbance effects. A significantly enhanced light scattering (RALLS) response was observed for

669 the oil with the lowest oxygen content ( 6 wt-\% d.b.), while oil obtained over the coked catalyst

670 with an oxygen content of $17 \mathrm{wt}-\%$ d.b showed a light scattering intensity close to the SiC oil. The

671 high aromaticity of the more severely deoxygenated oil seems to absorb at the used wavelength of

$672670 \mathrm{~nm}$, indicating extended conjugations for the higher MW compounds.

673 Since aromatics such as benzene, toluene, and xylenes (BTX) are of high value, their selectivity

674 within the quantified monoaromatics is of interest (see Figure 7). Clearly, the selectivity for BTX

675 compounds decayed at higher B:C ratios. This is in line with results reported for systems utilizing

676 high catalyst to biomass ratio, i.e. $\mathrm{B}: \mathrm{C}<<1$, where benzene and toluene are reported as the main

677 liquid products (but at low yields) [54]. For tests conducted with 151 g catalyst up to B:C $=6.2$,

678 the benzene selectivity hardly changed, while the selectivity for the toluene and xylene fraction

679 both decreased by about 33\% compared to their initial value over a non-coked catalyst. The

680 selectivity of substituted monoaromatic rings including alkyl and alkenyl-benzenes, as well as

681 indanes and indenes increases at higher $\mathrm{B}: \mathrm{C}$ ratios to about twice the amount compared to the 682 initial selectivity over a fresh catalyst. This indicates less effective side chain cracking and 683 dealkylation of alkylaromatics with increasing coke formation. 
684

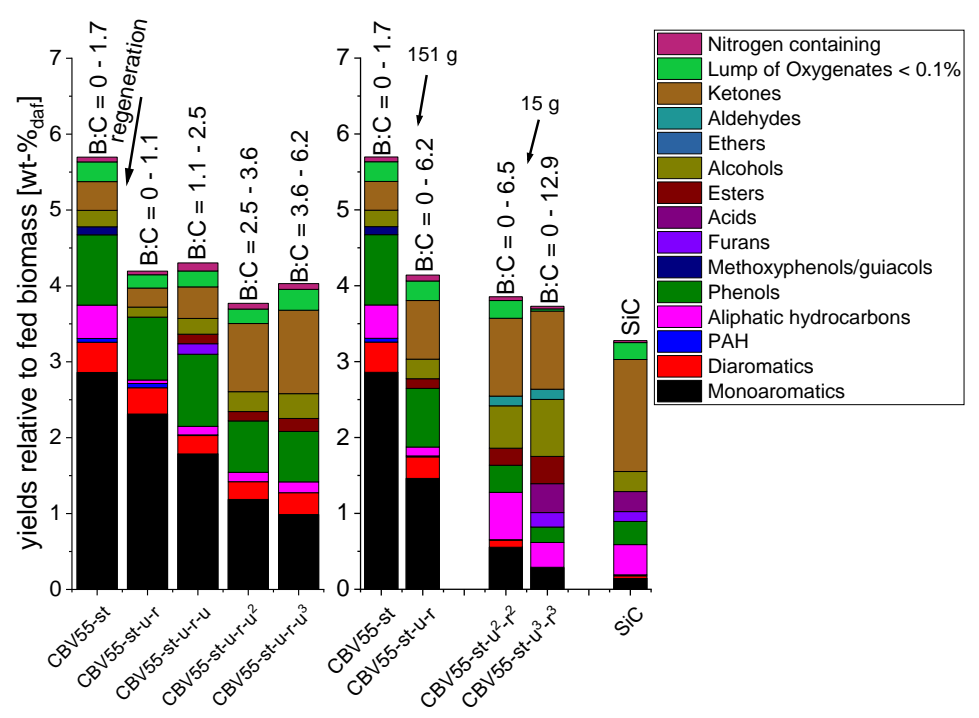

685 Figure 6. Liquid product characterization by GC-MS/FID: to the left, oil obtained for B:C $=0-$

6861.7 (CBV55-st) and four experiments with stepwise increasing B:C in the range $0-6.2$ (CBV55-

687 st-u-r). To the right, oils obtained at B:C $=0-1.7$ and $0-6.2$ over $151 \mathrm{~g}$ catalyst are compared with 688 oils obtained at B:C $=0-6.5$ and $0-12.9$ using $15 \mathrm{~g} \mathrm{CBV} 55$ and the $\mathrm{SiC}$ oil. Oxygenates in yields $689<0.1 \mathrm{wt}-\%$ have been lumped to "Lump of Oxygenates $<0.1 \mathrm{wt} \%$ ".

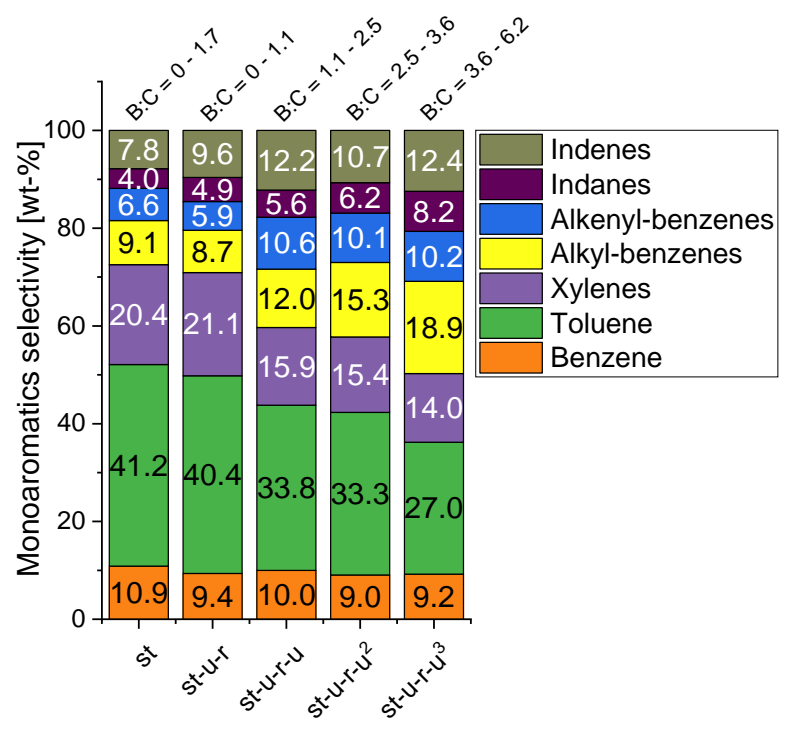

690

691 Figure 7. Selectivity for monoaromatics as quantified by GC-MS/FID obtained from upgrading 692 successive pyrolysis vapors up to B:C $=6.2$ over $151 \mathrm{~g} \mathrm{CBV55-st.} \mathrm{For} \mathrm{each} \mathrm{experiment,} \mathrm{the} \mathrm{five}$ 
693 liquid fractions obtained at different condensation stages were analyzed separately and according

694 to their organics content the selectivity is shown for the total organic liquid.

695 Revaporization efficiency. Conventional petroleum fuels, such as diesel or gas turbine fuels, 696 have a 10 - 90 wt- $\%$ distillation between $220-300{ }^{\circ} \mathrm{C}$ and $190-240{ }^{\circ} \mathrm{C}$, respectively. Bio-crude 697 reheating will be required for hydroprocessing these hydrocarbon-rich intermediates into gasoline 698 and diesel fuels. Following the recommendation by Venderbosch [48], the charring behavior of 699 the liquid product was investigated by TGA to evaluate the properties of the produced oils. The 700 Research Triangle Institute (RTI) has been developing a methodology to define the thermal 701 stability of bio-crude and determine if the extent of deoxygenation can be correlated with the 702 residual solids remaining after distilling the liquids up to $350{ }^{\circ} \mathrm{C}$ [55]. It was found that the 703 revaporization efficiency improves with decreasing oxygen content of the bio-oils with little 704 influence of the catalyst or feedstock type used. In this work, TGA-simulated distillation curves 705 were obtained both for the separate oil fractions obtained at each condensation stage (Figure S9), 706 as well as for the mixture of OF according to their yields (Figure 8a). The amount of remaining 707 char relative to the oil (d.b.) is reduced from $29.2 \%$ for the $\mathrm{SiC}$ case to $10.5 \%$ for the oil obtained 708 during $\mathrm{B}: \mathrm{C}=0-1.1$, and it increases to $22.3 \%$ for the oil obtained during $\mathrm{B}: \mathrm{C}=3.6-6.2$. Upon 709 heating, the $-60^{\circ} \mathrm{C}$ OFs loose $>80 \%$ of their mass below $200{ }^{\circ} \mathrm{C}$. This agrees well with the observed 710 increased range of $\mathrm{GC}$ detectable compounds for oils recovered at $-60{ }^{\circ} \mathrm{C}$ and the low charring 711 tendency is an important aspect to consider for further processing, e.g. hydrotreating, as less than $7125 \%$ char remained at $300^{\circ} \mathrm{C}$,. While the oil yield over a fresh catalyst is low ( $\left.14 \mathrm{wt} \% \mathrm{daf}\right)$, the extent 713 of possible reheating of the liquids has to be considered when gauging the optimal B:C ratio at 714 which the regeneration should be initiated. For the ESP oil fractions, the mass remaining at $350^{\circ} \mathrm{C}$ 715 is reduced from $28.4 \%$ for the $\mathrm{SiC}$ case to $18.8 \%$ for $\mathrm{B}: \mathrm{C}=0-1.1$ and further increases to $24.7 \%$ 
716 for $\mathrm{B}: \mathrm{C}=3.6-6.2$. The improved revaporization efficiency of bio-oils with reduced oxygen 717 content agrees with Dayton et al. `s findings [55] (Figure 8b).
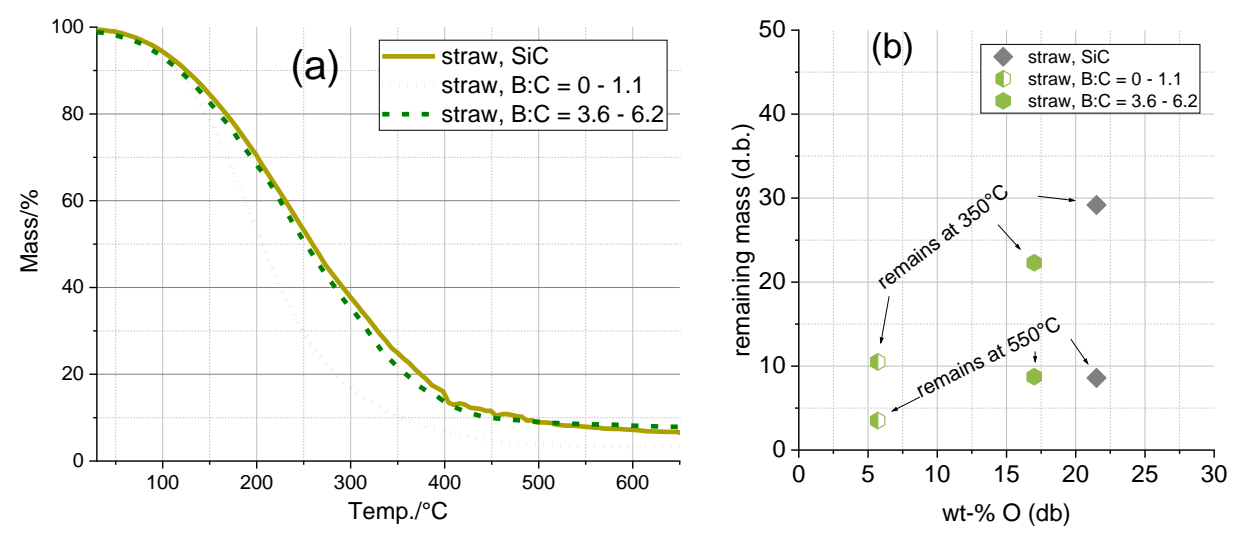

719 Figure 8. (a) TGA simulated distillation behavior conducted for $\sim 20 \mathrm{mg}$ oil with heating ramp $72050^{\circ} \mathrm{C} / \mathrm{min}$ to $650{ }^{\circ} \mathrm{C}$ under $150 \mathrm{ml} / \mathrm{min} \mathrm{N}_{2}$. The oils (sum OF) were prepared according to their 721 yields at each condensation stage. OFs were obtained for $\mathrm{SiC}$ bed and for $\mathrm{B}: \mathrm{C}=0-1.1$ and $\mathrm{B}: \mathrm{C}=$ $7223.6-6.2$, respectively when straw vapors were passed over $151 \mathrm{~g} \mathrm{CBV} 55$-st. (b) Correlation of the 723 oils oxygen content with the remaining mass (char) at $350{ }^{\circ} \mathrm{C}$ and $550{ }^{\circ} \mathrm{C}$, corrected by the oils 724 moisture content.

$725{ }^{1} \mathbf{H}$ NMR results. The processed ${ }^{1} \mathrm{H}$ NMR spectra of the obtained oil fractions of the $\mathrm{SiC}$ case, 726 and from upgrading over CBV55-st-u-r $(\mathrm{B}: \mathrm{C}=0-1.1$ and $\mathrm{B}: \mathrm{C}=3.6-6.2)$ obtained at the different 727 condensation stages are provided as supporting information (Figure S10 - S12). For each 728 condensation stage, it was chosen to show the non-catalytic oil at the top, followed by oil from a 729 coked catalyst during $\mathrm{B}: \mathrm{C}=3.6-6.2$ (middle) and oil obtained over a fresh catalyst during $\mathrm{B}: \mathrm{C}=$ $7300-1.1$ (bottom). This way, comparing the spectra from the bottom to top illustrates the changes 731 the oil fraction undergoes with ongoing catalyst deactivation (assuming that the non-catalytic 732 reference case will be approached by an infinitely large B:C ratio). The relative distribution of the 733 different chemical groups could be obtained by assigning the functional groups to their chemical 
734 shift ranges. The water region $(3.6-3.3 \mathrm{ppm})$ was excluded for this comparison. The obtained

735 hydrogen percentages for the different oil fractions are summarized in Table 5. A higher content

736 of aromatic and conjugated alkene hydrogen $(8.2-6.0 \mathrm{ppm})$ results for the oil obtained at low B:C

737 compared to the non-catalytic reference. Precisely, the aromatic $\mathrm{H}$ content for the $4^{\circ} \mathrm{C}$ OFs and -

$73860^{\circ} \mathrm{C} \mathrm{OFs} \mathrm{is} \mathrm{about} \mathrm{four} \mathrm{times} \mathrm{higher} \mathrm{than} \mathrm{for} \mathrm{the} \mathrm{non-catalytic} \mathrm{reference,} \mathrm{while} \mathrm{for} \mathrm{the} \mathrm{ESP} \mathrm{OFs} \mathrm{it}$

739 is about twice as high. Since the exchangeable proton of phenols might appear at the region of 8.2

$740-6.0 \mathrm{ppm}$ as well, the contribution of $\mathrm{H}$ bound within hetero-aromatic rings cannot be excluded.

741 While hydrogen contributions from oxygen-containing groups $(6.0-3.6 \mathrm{ppm})$ are almost

742 completely absent at low B:C ratio, they start to appear for the oil obtained from a vapor upgrading

743 over a coked catalyst $(\mathrm{B}: \mathrm{C}=3.6-6.2)$. This is in agreement with the reduced oxygen content of

744 the upgraded oils determined by elemental analysis. It is interesting to note the increase in $\mathrm{CHO}$

745 or $\mathrm{ArOH}$ groups towards lower B:C ratio for the $4^{\circ} \mathrm{C} \mathrm{OF}$ and $\mathrm{ESP}$ OF, whereas the $-60^{\circ} \mathrm{C}$ OF show

746 the opposite trend. This could be explained by an increased amount of ArOH containing

747 compounds condensed at the $4^{\circ} \mathrm{C}$ OF and ESP condensation stage at low B:C ratios, whereas the

748 dry ice trap condenses light aldehyde or ketone compounds, which are effectively converted at low

749 B:C ratio with higher catalyst activity.

750 Table 5. Hydrogen percentage based on the ${ }^{1} \mathrm{H}$ NMR analysis of bio-oils obtained from passing

751 straw fast pyrolysis vapors over $\mathrm{SiC}$ bed (a), over CBV55-st-u-r during $\mathrm{B}: \mathrm{C}=3.6-6.2$ (b), and

752 over CBV55-st-u-r during B:C $=0-1.1$ (c).

\begin{tabular}{|l|c|c|c|c|c|c|c|c|c|c|}
\hline & \multicolumn{3}{|c|}{$\mathrm{H}-\%$ for $4{ }^{\circ} \mathrm{C}$ OF } & \multicolumn{2}{|c|}{$\mathrm{H}-\%$ for ESP OF } & \multicolumn{2}{c|}{$\mathrm{H}-\%-60{ }^{\circ} \mathrm{C}$ OF } \\
\hline Assignment & $\begin{array}{c}\text { Chemical } \\
\text { shit range } \\
\text { (ppm) }\end{array}$ & $\mathrm{a}$ & $\mathrm{b}$ & $\mathrm{c}$ & $\mathrm{a}$ & $\mathrm{b}$ & $\mathrm{c}$ & $\mathrm{a}$ & $\mathrm{b}$ & $\mathrm{c}$ \\
\hline -COOH & $12.5-11$ & $0.0 \%$ & $0.0 \%$ & $0.1 \%$ & $0.0 \%$ & $0.0 \%$ & $0.1 \%$ & $0.0 \%$ & $0.0 \%$ & $0.0 \%$ \\
\hline $\mathrm{CHO}, \mathrm{ArOH}$ & $11-8.2$ & $0.1 \%$ & $2.8 \%$ & $3.5 \%$ & $1.3 \%$ & $3.0 \%$ & $3.8 \%$ & $2.5 \%$ & $1.7 \%$ & $1.2 \%$ \\
\hline $\begin{array}{l}\text { Aromatics } \\
\text { and } \\
\begin{array}{l}\text { conjugated } \\
\text { alkene H }\end{array}\end{array}$ & $8.2-6$ & $7.8 \%$ & $21.6 \%$ & $35.4 \%$ & $14.8 \%$ & $21.7 \%$ & $31.4 \%$ & $7.8 \%$ & $25.6 \%$ & $38.6 \%$ \\
\hline
\end{tabular}




\begin{tabular}{|c|c|c|c|c|c|c|c|c|c|c|}
\hline $\begin{array}{l}\text { Aliphatic } \mathrm{OH}, \\
-\mathrm{CH}=\mathrm{CH}- \\
\mathrm{Ar}-\mathrm{CH}_{2}-\mathrm{O}-\mathrm{R}\end{array}$ & $6-4.2$ & $1.6 \%$ & $1.2 \%$ & $0.4 \%$ & $2.7 \%$ & $2.3 \%$ & $0.4 \%$ & $5.9 \%$ & $3.0 \%$ & $0.8 \%$ \\
\hline $\begin{array}{l}\mathrm{R}-\mathrm{CH}_{2}-\mathrm{O}-\mathrm{R}, \\
\mathrm{CH} 3-\mathrm{O}-\mathrm{R}\end{array}$ & $4.2-3.6$ & $17.9 \%$ & $4.6 \%$ & $0.6 \%$ & $10.5 \%$ & $7.8 \%$ & $1.5 \%$ & $9.7 \%$ & $0.0 \%$ & $0.1 \%$ \\
\hline $\begin{array}{l}-\mathrm{CH}_{2} \mathrm{C}=\mathrm{O}, \\
-\mathrm{CHR}-\mathrm{C}=\mathrm{C}, \\
\text { aliphatic } \mathrm{H}\end{array}$ & $3.3-2$ & $54.1 \%$ & $48.0 \%$ & $54.7 \%$ & $37.1 \%$ & $50.7 \%$ & $56.1 \%$ & $28.4 \%$ & $44.9 \%$ & $52.5 \%$ \\
\hline Aliphatic H & $2-0$ & $18.4 \%$ & $21.7 \%$ & $5.3 \%$ & $33.6 \%$ & $14.5 \%$ & $6.7 \%$ & $45.6 \%$ & $24.8 \%$ & $6.7 \%$ \\
\hline
\end{tabular}

$754{ }^{13} \mathrm{C}$ NMR results. The processed ${ }^{13} \mathrm{C}$ NMR spectra of the obtained oil fractions of the $\mathrm{SiC}$ case, 755 and from upgrading over CBV55-st-u-r $(\mathrm{B}: \mathrm{C}=0-1.1$ and $\mathrm{B}: \mathrm{C}=3.6-6.2)$ obtained at the different 756 condensation stages are provided as supporting information (Figure S13 - S15). The ${ }^{13} \mathrm{C}$ NMR 757 spectrum offers the advantage of less overlap of chemical shifts compared to ${ }^{1} \mathrm{H}$ NMR. The 758 assignment of chemical shift regions was conducted according to Mante et al. [56] and Joseph et 759 al. [57]. The carbon distributions obtained by integrating the ${ }^{13} \mathrm{C}$ NMR spectrum of the oils 760 obtained during the different levels of catalyst activity for each condensation stage are summarized 761 in Table S26. The ${ }^{13} \mathrm{C}$ NMR analysis confirms a clear influence of the catalyst on the chemical 762 composition of the bio-oil. Oil fractions obtained from the non-catalytic run show a high amount 763 of oxygenated compounds with carbonyl, carbohydrates and methoxy/hydroxyl carbons 764 constituting $37 \%$ and $43 \%$ of the total $\mathrm{C}$ for the $4{ }^{\circ} \mathrm{C}$ OF and ESP OF, respectively. For the oil 765 obtained over a coked CBV55 catalyst (B:C $=3.2-6.2)$, the amount of oxygenated compounds in 766 the two stages is reduced to $35 \%$ and $34 \%$, respectively. The content of carbohydrates were 767 eliminated significantly at low B:C ratio, and are almost under the limit of detection. Note the 768 overall closely related trends in terms of chemical group composition for the oils collected at 769 different condensation stages, despite their large differences in terms of viscosity and boiling point 770 range. Comparing the oil fractions obtained using $\mathrm{SiC}$ with $\mathrm{B}: \mathrm{C}=0-1.1$ ( CBV55-st-u-r), the 771 carbon related to oxygenated compounds of the $4^{\circ} \mathrm{C}$ OF was reduced by $31 \%$, while a reduction 772 of carbon bound to oxygen of $57 \%$ and $62 \%$ is observed for the ESP OF and $-60^{\circ} \mathrm{C}$ OF. Based on 
773 the oil yield distribution at the different condensation stages, the characteristics for the sum of oil

774 fractions can be estimated, as shown in Table 6. With increased amount of pyrolysis vapors passed

775 over the zeolite, the carbonyl, carbohydrates, alcohols, ethers, lignin derived methoxy carbon and

776 alkyl fraction increased, whereas the aromatics content rapidly decreased.

777 Table 6. Carbon distribution for sum of OFs according to ${ }^{13} \mathrm{C}$ NMR characterization of $4{ }^{\circ} \mathrm{C} \mathrm{OF}$, 778 ESP OF and $-60^{\circ} \mathrm{C}$ OF, shown for oil obtained from (a) SiC bed, (b) over CBV55-st-u-r during $779 \quad \mathrm{~B}: \mathrm{C}=3.6-6.2$ and (c) over CBV55-st-u-r during $\mathrm{B}: \mathrm{C}=0-1.1$.

\begin{tabular}{|l|c|c|c|c|c|c|}
\hline & $\begin{array}{c}\text { Yield of sum OF } \\
\text { [wt-\%daf] }\end{array}$ & Carbonyl & Aromatics & $\begin{array}{c}\text { Carbohydrates, alcohols, } \\
\text { ethers }\end{array}$ & Methoxy in lignin & Alkyl \\
\hline $\mathrm{a}$ & $19.4 \%$ & $17.8 \%$ & $27.7 \%$ & $16.9 \%$ & $2.9 \%$ & $25.7 \%$ \\
\hline $\mathrm{b}$ & $13.3 \%$ & $17.3 \%$ & $43.6 \%$ & $11.5 \%$ & $2.6 \%$ & $25.0 \%$ \\
\hline $\mathrm{c}$ & $7.2 \%$ & $7.1 \%$ & $62.6 \%$ & $7.5 \%$ & $2.2 \%$ & $20.7 \%$ \\
\hline
\end{tabular}

2D NMR-results. Even though the 1D NMR characterization techniques are essential for

782 quantification, they suffer from spectral overlapping or long relaxation times when applied in the 783 bio-oil analysis [58]. 2D NMR spectra lower the likelihood of overlapping because the signals are 784 spread out into two dimensions. The heteronuclear single-quantum correlation spectroscopy 785 (HSQC) experiment provide single-band connection between protons and carbons. The 786 multiplicity-edited HSQC spectrum correlates chemical shifts of carbons and protons in a phase 787 sensitive way. Methine $(=\mathrm{CH}-)$ and methyl $\left(-\mathrm{CH}_{3}\right)$ groups will appear as positive signals (blue) 788 whereas methylene groups $\left(=\mathrm{CH}_{2}\right.$ or $\left.-\mathrm{CH}_{2}-\right)$ will present negative intensity (red). A comparison 789 of the 2D NMR spectra of the different oil fractions is found in the supporting information (see 790 Figure S16 and S18). For oil collected at B:C = 3.6 - 6.2 (CBV55) the content of sugar derived 791 compounds and alcohols is still partly reduced compared to the $\mathrm{SiC}$ oils. The same holds true for 792 aldehydes and to some extent for acid derived compounds. The oil fractions obtained at B:C $=0-$ 
7931.1 stand out by absence of aldehyde compounds, sugar derived compounds/alcohols and methoxy 794 groups.

795 Non-condensable gases. The formation of dry gas and coke is reduced with increasing catalyst 796 deactivation. Figure 9 shows the yields of $\mathrm{C}_{2}$ to $\mathrm{C}_{4}$ olefins during $\mathrm{B}: \mathrm{C}=0-1.7$ over CBV55-st 797 and four successive upgrading steps over the regenerated zeolite. The ethene yield peaked at $3.1 \%$ 798 for CBV55-st and at 2.4\% after the first regeneration, and it decreased towards higher B:C ratios 799 until leveling out at $\sim 1.4 \mathrm{wt} \%$. For propene, the yield only slightly decreased at values $\sim 3.7 \mathrm{wt}-$ $800 \%$ for CBV55-st, whereas after the first regeneration cycle the propene yield dropped more rapidly, 801 reaching $\sim 2 \mathrm{wt}-\%$ at $\mathrm{B}: \mathrm{C}>6$. n-butenes increased up to $\mathrm{B}: \mathrm{C} \sim 2$ after which the yield declined 802 towards higher B:C ratios. For CBV55-st, the yield of iso-butene reached a peak at B:C $\sim 0.8$ after 803 which the yield slowly dropped. After a first coke-burn off, this peak occurred at B:C $\sim 0.5$. Further 804 gas composition ratios are discussed in the supporting information (Figure S19).
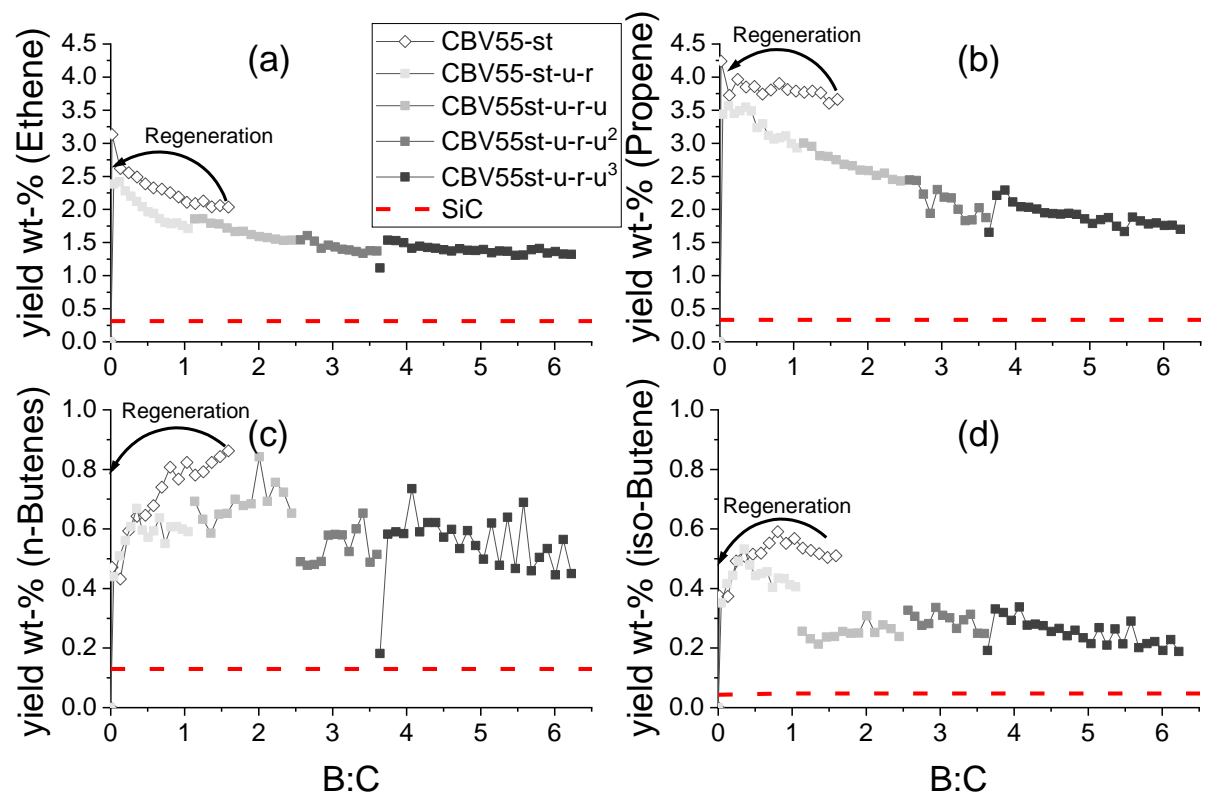

805

$\mathrm{B}: \mathrm{C}$

$\mathrm{B}: \mathrm{C}$ 
806 Figure 9. Yield of $\mathrm{C}_{2}$ to $\mathrm{C}_{4}$ olefins during increasing $\mathrm{B}: \mathrm{C}$ ratio over CBV55-st (diamond symbol)

807 and after one oxidative regeneration (squares); The legend in (a) is also valid for plots (b) to (d).

808 The yields obtained from non-catalytic SiC experiment are shown as reference (red dashed line).

809 Discussion

810 At low B:C ratio, a high deoxygenation activity results with high yields of $\mathrm{CO}, \mathrm{CO}_{2}, \mathrm{H}_{2} \mathrm{O}$, and 811 coke, but at a low oil yield. The obtained oil has desirable properties in terms of reduced acidity 812 and high HHV. With increasing amount of biomass pyrolysis vapors fed over the catalyst, the 813 catalyst deactivates by coke deposition, blocking the access to active sites. Thus, the oil yield 814 increases at the expense of inferior oil quality. The increasing oil yield with higher B:C ratio also 815 increases the energy recovery into the liquid product. The critical point at which the feeding of 816 biomass pyrolysis vapors over the catalyst should be stopped and the regeneration initiated will 817 depend on the process utilizing the oil and its requirements to the oil`s quality.

818 It is of interest to compare our results with other studies, which also varied the exposure of 819 biomass derived pyrolysis vapors over HZSM-5 at similar operating temperature of $450-550{ }^{\circ} \mathrm{C}$.

820 To allow better comparison of the obtained oil yields, only results reported for ex-situ upgrading 821 are taken into account. Despite the vast amount of research devoted to catalytic fast pyrolysis, 822 often important information as the oils oxygen content or the used biomass to catalyst ratio are 823 missing. Only few references could be found which were devoted to wood and rice husk as 824 feedstock. To the best of our knowledge, no detailed investigation for the change in oil quality for $825 e x$-situ catalytically upgraded wheat straw derived vapors is available. The reported oil yields on 826 dry-ash-free biomass basis and its oxygen content (d.b.) was related based on increasing dry, ash827 free biomass to catalyst ratios, and therefore increasing deactivation of the catalyst (Figure 10). 828 With increasing B:C ratio, a steep increase in oxygen content for oils from woody biomass and 
829 acid washed straw [60] is observed compared to the results obtained in this study. It appears that

830 both the oxygen content and oil yield increase asymptotically towards oils obtained from non-

831 catalytic reference cases ( $\sim 35 \mathrm{wt}-\%$ oxygen at $30 \mathrm{wt}-\%$ oil yield for woody biomass and acid

832 washed straw). For most of these studies, at B:C $>3$ the catalyst appears completely deactivated.

833 In comparison, a reduced oxygen content for the straw derived oils from this study is observed

834 extending to higher B:C ratios; however, also the liquid yields are lower which may be attributed

835 partly to the high indigenous ash content of the straw feedstock, which is known to promote the

836 formation of chars and gas [59].

837 Few studies $[6,14,61,62]$ have investigated the possibility of co-processing CFP oils with 838 vacuum gas oil by blending $10-20 \%$ of bio-oil. The oil`s oxygen content ranged from 20 to 27 $839 \mathrm{wt} \%$ in these studies. The oil`s maximum oxygen content and functionalities to allow successful 840 processing in a refinery thus determine the $\mathrm{B}: \mathrm{C}$ ratio at which the vapor upgrading must be stopped, 841 thereby dictating the frequency of catalyst regeneration. When fitting the results found in the 842 literature for woody biomass and acid washed straw by an exponential decay function, it can be 843 estimated that for an oxygen content of $\sim 15 \%$ the catalyst regeneration for woody biomass would 844 need to be initiated at a B:C ratio of about 1 , whereas for the straw derived oils a six fold amount 845 of biomass could be converted over the same amount of catalyst before regeneration needs to be

846 initiated. A reduced regeneration frequency will extend catalyst lifetime and in general ease the 847 operation. While Figure 10 was devoted to comparing the results of the obtained liquid from start 848 over the fresh catalyst to a certain B:C ratio, we can also try to compare the oils collected during 849 increasing B:C intervals. The work by Horne and Williams [28] allows this comparison for oils 850 obtained from ex-situ vapor upgrading (fast pyrolysis of mixed wood). Suitably, these authors used 851 a similar condensation train comprised of a cooling water and dry ice stage. However, the oxygen 
852 content in the collected oil phase was stated on wet basis without analyzing the water content. We

853 therefore show our results for oxygen content and yields on wet basis for the phase separated oil

854 fractions to facilitate the comparison (Figure 11). Similar trends are observed for the oil collected

855 from stepwise upgrading. While lower oil yields result for the straw derived oils, their oxygen

856 content on wet basis at a given B:C ratio is only about 50\% compared to that of the wood derived

857 oils.
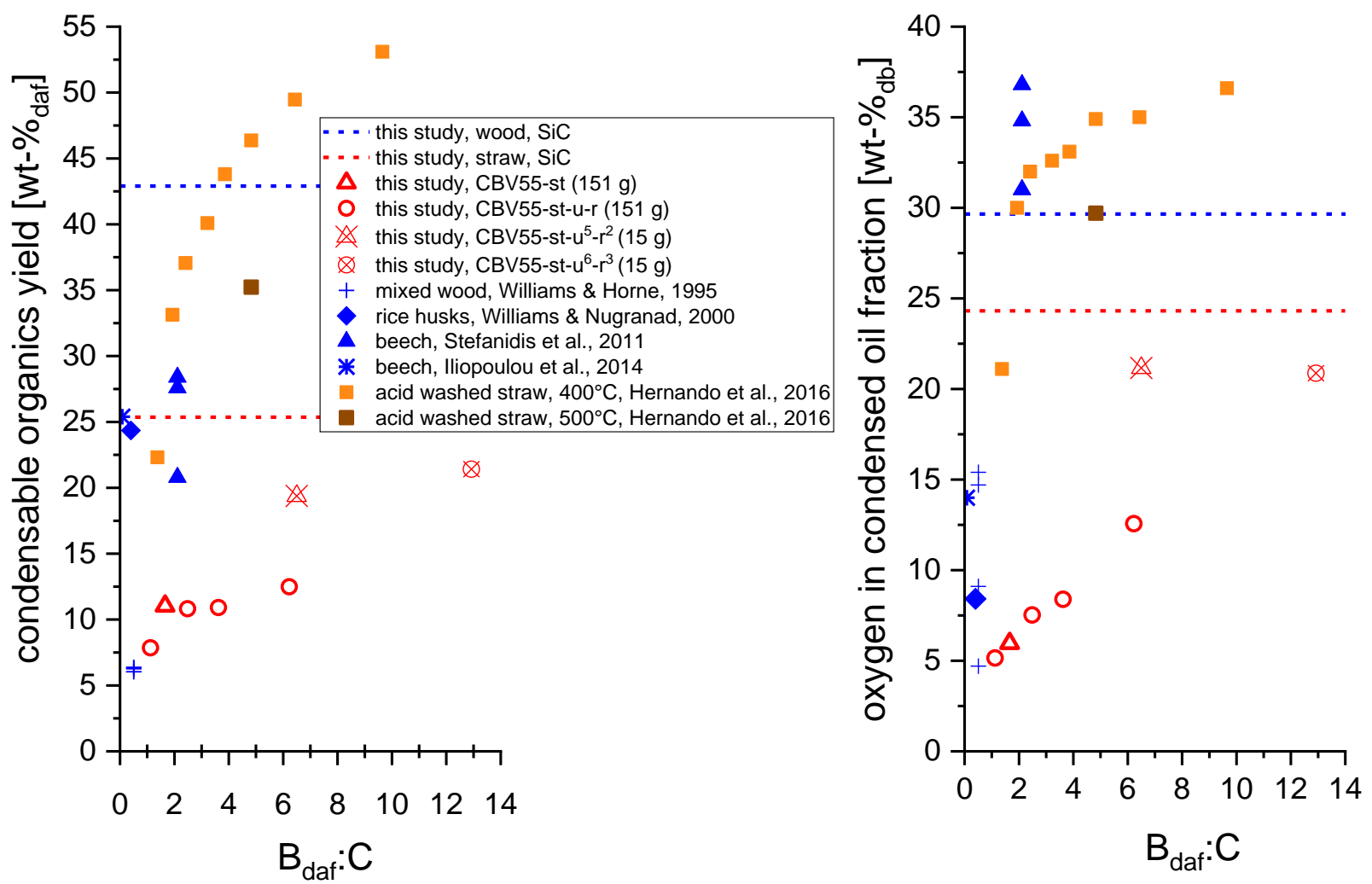

859 Figure 10. Comparison of results obtained from this study (open symbols) for upgrading straw

860 pyrolysis vapors with results found in the literature for ex-situ upgrading over ZSM-5 type zeolites

861 at different $\mathrm{B}: \mathrm{C}$ ratios and catalyst temperatures of $500^{\circ} \mathrm{C}$. Shown are the "cumulative" oil

862 properties when collected at the indicated daf biomass to catalyst ratios. Square symbols refer to

863 the study of Hernando et al. [60] using acid-washed wheat straw (pyrolysis at $550^{\circ} \mathrm{C}$ ) and

864 upgrading the vapors over ZSM-5 at $400^{\circ} \mathrm{C}$ for various B:C ratios and a single test at $500{ }^{\circ} \mathrm{C}$. 
865 Diamond symbols refer to results from Williams and Nugranad [3] obtained for rice husks, the 866 triangle symbols at the same $\mathrm{B}: \mathrm{C}$ ratio are obtained for different $\mathrm{SiO}_{2} / \mathrm{Al}_{2} \mathrm{O}_{3}$ contents of $\mathrm{ZSM}-5$ 867 with beech wood feedstock [2], star symbols refer to results by Iliopoulou et al. [4] for beech wood, 868 and the cross symbols refer to results by Williams and Horne [28] reported for mixed wood 869 feedstock and repeated regeneration steps which were found to increase the oil's oxygen content 870 with minor increase in oil yield. Results obtained for the non-catalytic reference case of this study 871 are indicated by horizontal lines for both wood and straw feedstock.

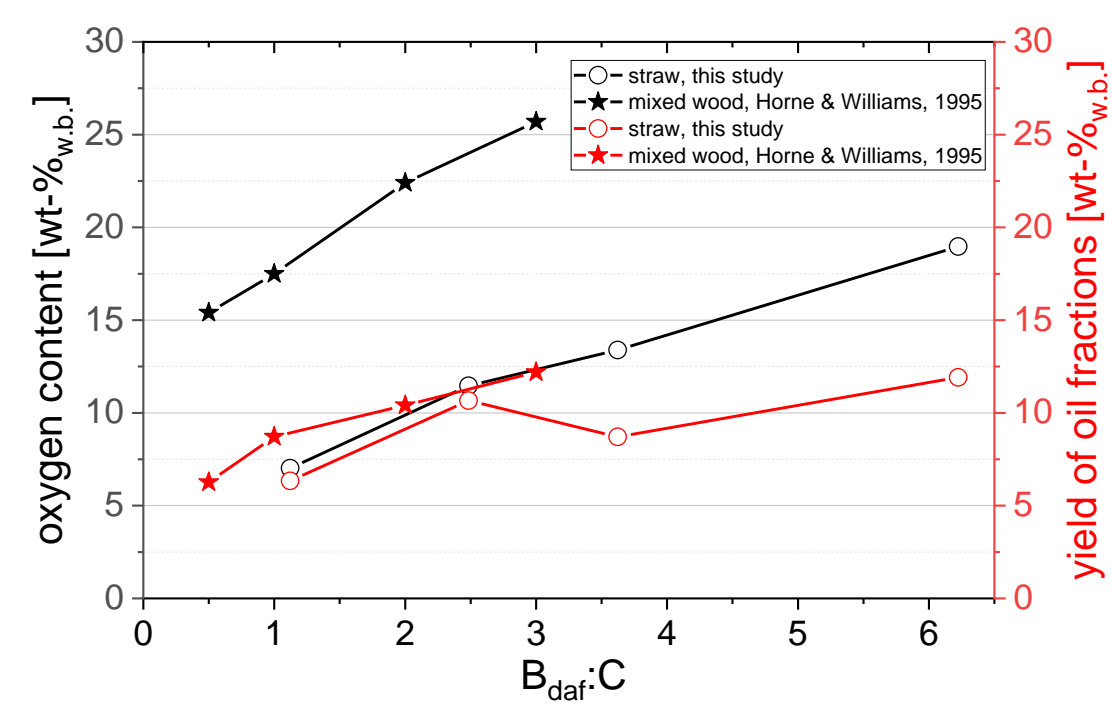

872

873 Figure 11. Change in the "differential" oil yields (including moisture) and oxygen content (on wet

874 basis) shown for this study (straw) and results obtained by Horne \& Williams [10] for upgrading

875 pyrolysis vapors derived from mixed wood (daf) for the intervals $\mathrm{B}: \mathrm{C}=0-0.5 ; 0.5-1,1-2$, and

$8762-3$. Shown is the yield of oil fractions, i.e. without taking $\mathrm{C}_{4+}$ and aqueous fractions into account.

\section{Conclusion}

878 The change in oil yield during ex-situ CFP of wheat straw over an increasingly coked ZSM-5 was

879 correlated with the changes in oil quality. We complemented the assessment of catalyst activity by

880 detailed characterization of both the liquid and gas phase products. With increasing deactivation 
881 due to coking, the yields of valuable hydrocarbon product fractions, particularly aromatics and

882 olefins decreased, while a gradual breakthrough of primary pyrolysis vapors increased the oxygen

883 content of the condensed liquid. Bio-crude produced with ZSM-5 at B:C $=1.7$ contained higher

884 yields of completely deoxygenated compounds such as monoaromatics ( $3 \mathrm{wt}-\%$ of daf biomass)

885 compared to the non-catalytic oil, but also elevated yields of phenols $(0.9 \mathrm{wt}-\%)$. While aldehydes,

886 sugars, alcohols and methoxy groups were effectively converted at low B:C ratio, they can be

887 found in increasing amounts in the liquid product slate at a progressed zeolite deactivation. The

888 catalyst maintained activity after steaming and four cycles of vapor upgrading and oxidative

889 regeneration, and the zeolite`s acidity decreased by $18 \%$ relative to the steamed zeolite. While the

890 results indicate catalyst stability over few reaction-regeneration cycles, investigation of the 'true'

891 long-term stability would require many additional regeneration cycles.

892 The hot gas filtration upstream the zeolite bed was effective in preventing accumulation of

893 potassium on the zeolite. We conclude that the regeneration frequency will depend on the product

894 application. In agreement with CFP of woody biomass reported in literature, the selective 895 production of monoaromatics and olefins can only be achieved at low B:C ratios and requires 896 continuous catalyst regeneration. For fuel production, a high energy yield is paramount which may 897 allow operation toward higher B:C ratio and thereby require reduced regeneration frequency as 898 long as certain fuel requirements are met. The provided characterization of the oil properties in 899 combination with the regeneration and deactivation of the catalyst may assist the development of 900 co-processing of CFP oil from agricultural residues in oil refineries.

901 ASSOCIATED CONTENT

902 Supporting Information. $\mathrm{NH}_{3}$-TPD profiles; Isotherms and pore distribution of fresh and used

903 catalyst obtained from $\mathrm{N}_{2}$ and Ar physisorption; XRD spectra for fresh and used catalyst; $\mathrm{CO}$ 
904 and $\mathrm{CO}_{2}$ gas profile during regeneration; Catalyst bed temperature profiles during upgrading;

905 Distribution of collected liquids according to condensation stage; Moisture content, HHV and

906 elemental analysis of oil and aqueous fractions; GC-MS/FID identified compounds and product

907 grouping; SEC oil characterization; TGA simulated distillation curves; quantitative ${ }^{1} \mathrm{H}$ NMR and

$908{ }^{13} \mathrm{C}$ NMR spectra; HSQC NMR spectra for oils collected at different condensation stages.

909 AUTHOR INFORMATION

910 Corresponding Author

$911 * a j @ k t . d t u . d k$

\section{$912 \quad$ Funding Sources}

913 Partial funding by the Energy Technology Development and Demonstration Program (EUDP

914 project number 12454) of the PhD project conducted at the CHEC Research Center, DTU

915 Chemical Engineering is acknowledged.

916 ACKNOWLEDGMENT

917 Postdoctoral researcher Leonhard Schill (DTU, Department of Chemistry) is acknowledged for

918 conducting $\mathrm{NH}_{3}$-TPD measurements. Peter Wiwel (Haldor Topsøe) is acknowledged for 919 conducting the total sulfur determination of bio-oil samples.

\section{ABBREVIATIONS}

921 CFP, catalytic fast pyrolysis; daf, dry ash-free basis; d.b., dry basis; ECN, effective carbon

922 number; ESP, electrostatic precipitator; FP, fast pyrolysis; HHV, higher heating value; ID, inner

923 diameter; RI, refractive index; SEC, size exclusion chromatography; TGA, thermogravimetric

924 analysis; OF, oil fraction; WF, water fraction; 


\section{REFERENCES}

926 [1] G. Perkins, T. Bhaskar, M. Konarova, Process development status of fast pyrolysis 927 technologies for the manufacture of renewable transport fuels from biomass, Renew. 928 Sustain. Energy Rev. 90 (2018) 292-315. doi:10.1016/j.rser.2018.03.048.

929 [2] S.D. Stefanidis, K.G. Kalogiannis, E.F. Iliopoulou, A.A. Lappas, P.A. Pilavachi, In-situ 930 upgrading of biomass pyrolysis vapors: Catalyst screening on a fixed bed reactor, Bioresour. 931 Technol. 102 (2011) 8261-8267. doi:10.1016/j.biortech.2011.06.032.

932 [3] P.T. Williams, N. Nugranad, Comparison of products from the pyrolysis and catalytic 933 pyrolysis of rice husks, Energy. 25 (2000) 493-513. doi:10.1016/S0360-5442(00)00009-8.

934 [4] E.F. Iliopoulou, S.D. Stefanidis, K. Kalogiannis, A.C. Psarras, A. Delimitis, K.S. 935 Triantafyllidis, A.A. Lappas, Pilot-scale validation of Co-ZSM-5 catalyst performance in 936 the catalytic upgrading of biomass pyrolysis vapours, Green Chem. 16 (2014) 662-674. 937 doi:10.1039/C3GC41575A.

938 [5] G.W. Huber, Breaking the Chemical and Engineering Barriers to Lignocellulosic Biofuels : 939 Hydrocarbon Biorefineries, Am. Chem. Soc. (2007) 1-177.

940 [6] F.A. Agblevor, O. Mante, R. Mcclung, S.T. Oyama, Co-processing of standard gas oil and 941 biocrude oil to hydrocarbon fuels, Biomass and Bioenergy. 45 (2012) 130-137. 942 doi:10.1016/j.biombioe.2012.05.024.

943 [7] J. Jae, G.A. Tompsett, A.J. Foster, K.D. Hammond, S.M. Auerbach, R.F. Lobo, G.W. 944 Huber, Investigation into the shape selectivity of zeolite catalysts for biomass conversion, 945 J. Catal. 279 (2011) 257-268. doi:10.1016/j.jcat.2011.01.019. 
946 [8] A.J. Foster, J. Jae, Y. Cheng, G.W. Huber, R.F. Lobo, Optimizing the aromatic yield and 947 distribution from catalytic fast pyrolysis of biomass over ZSM-5, "Applied Catal. A, Gen. $948 \quad$ 423-424 (2012) 154-161. doi:10.1016/j.apcata.2012.02.030.

949 [9] The road to biobased BTX: The Digest's 2018 Multi-Slide Guide to Anellotech, (n.d.). 950 http://www.biofuelsdigest.com/bdigest/2018/08/13/the-road-to-biobased-btx-the-digests951 2018-multi-slide-guide-to-anellotech/22/ (accessed September 20, 2018).

952 [10] P.A. Horne, P.T. Williams, The effect of zeolite ZSM-5 catalyst deactivation during the 953 upgrading of biomass-derived pyrolysis vapours, J. Anal. Appl. Pyrolysis. 34 (1995) 65954 85. doi:10.1016/0165-2370(94)00875-2.

955 [11] J.W. Scahill, J.P. Diebold, Engineering aspects of upgrading pyrolysis oil using zeolites, $956 \quad$ ELSEVIER Sci. Publ. LTD. (1988) 927-940.

957 [12] M. Asadieraghi, W. Mohd, W.M.A. Wan Daud, H.F. Abbas, Heterogeneous catalysts for 958 advanced bio-fuel production through catalytic biomass pyrolysis vapor upgrading: a 959 review, RSC Adv. 5 (2015) 22234-22255. doi:10.1039/C5RA00762C.

960 [13] E. Taarning, C.M. Osmundsen, C. Mårup, S.I. Andersen, C.H. Christensen, X. Yang, B. 961 Voss, Zeolite-catalyzed biomass conversion to fuels and chemicals Zeolite-catalyzed 962 biomass conversion to fuels and chemicals, (2011). doi:10.1039/c004518g.

963 [14] N. Thegarid, G. Fogassy, Y. Schuurman, C. Mirodatos, S.D. Stefanidis, E.F. Iliopoulou, K. 964 Kalogiannis, A.A. Lappas, Second-generation biofuels by co-processing catalytic pyrolysis 965 oil in FCC units, Appl. Catal. B Environ. 145 (2014) 161-166. 966 doi:10.1016/j.apcatb.2013.01.019. 
967 [15] C. Lindfors, V. Paasikallio, E. Kuoppala, M. Reinikainen, A. Oasmaa, Co-processing of 968 Dry Bio-oil, Catalytic Pyrolysis Oil, and Hydrotreated Bio-oil in a Micro Activity Test Unit, 969 (2015). doi:10.1021/acs.energyfuels.5b00339.

970 [16] C. Wang, M. Li, Y. Fang, Coprocessing of Catalytic-Pyrolysis-Derived Bio-Oil with VGO 971 in a Pilot-Scale FCC Riser, Ind. Eng. Chem. Res. 55 (2016) 3525-3534. 972 doi:10.1021/acs.iecr.5b03008.

973 [17] P.A. Jensen, F.J. Frandsen, H. Wu, P. Glarborg, A review : Fly ash and deposit formation 974 in PF fired biomass boilers, Impacts Fuel Qual. Power Prod. (2016) 1-8.

975 [18] F.J. Frandsen, Ash Formation, Deposition and Corrosion when Utilizing Straw for Heat 976 and Power Production, (2011) 1-341.

977 [19] B. Melissari, Ash related problems with high alkalii biomass and its mitigation 978 experimental evaluation, Mem. Investig. En Ing. 12 (2014) 31-44.

979 [20] V. Paasikallio, C. Lindfors, E. Kuoppala, Y. Solantausta, A. Oasmaa, J. Lehto, J. Lehtonen, $980 \quad$ Product quality and catalyst deactivation in a four day catalytic fast pyrolysis production 981 run, Green Chem. 16 (2014) 3549-3559. doi:10.1039/c4gc00571f.

982 [21] T.J. Mazanec, J.P. Whiting, F. Pesa, R. Song, Y.-T. Cheng, R. Song, Regeneration of $983 \quad$ catalytic fast pyrolysis, US 2014/0303414 A1, 2017.

984 [22] J. Shi, C. Sorensen, T. Mazanec, R. Song, S. Goud, S. Han, Y.-T. Cheng, V.L. Frank, J.W.F. 985 Igoe, M. Schneidkraut, Improved catalytic fast pyrolysis process with impurity removal, $986 \quad$ WO2017003790A1, 2015.

987 [23] R.M. Baldwin, C.J. Feik, Bio-oil stabilization and upgrading by hot gas filtration, Energy 
$988 \quad$ and Fuels. 27 (2013) 3224-3238. doi:10.1021/ef400177t.

989 [24] I. Graça, F.R. Ribeiro, H.S. Cerqueira, Y.L. Lam, M.B.B. de Almeida, Catalytic cracking $990 \quad$ of mixtures of model bio-oil compounds and gasoil, Appl. Catal. B Environ. 90 (2009) 556991 563. doi:10.1016/j.apcatb.2009.04.010.

992 [25] A. V. Bridgwater, Review of fast pyrolysis of biomass and product upgrading, Biomass and 993 Bioenergy. 38 (2012) 68-94. doi:10.1016/j.biombioe.2011.01.048.

994 [26] C. Mukarakate, X. Zhang, A.R. Stanton, D.J. Robichaud, P.N. Ciesielski, K. Malhotra, B.S. 995 Donohoe, E. Gjersing, R.J. Evans, D.S. Heroux, R. Richards, K. Iisa, M.R. Nimlos, Real996 time monitoring of the deactivation of HZSM-5 during upgrading of pine pyrolysis vapors, 997 Green Chem. 16 (2014) 1444-1461. doi:10.1039/C3GC42065E.

998 [27] G. Yildiz, T. Lathouwers, H.E. Toraman, K.M. Van Geem, G.B. Marin, F. Ronsse, R. Van 999 Duren, S.R.A. Kersten, W. Prins, Catalytic fast pyrolysis of pine wood: Effect of successive 1000 catalyst regeneration, Energy and Fuels. 28 (2014) 4560-4572. doi:10.1021/ef500636c.

1001 [28] P.T. Williams, P.A. Horne, The influence of catalyst regeneration on the composition of 1002 zeolite-upgraded biomass pyrolysis oils, Fuel. 74 (1995) 1839-1851. doi:10.1016/0016$1003 \quad 2361(95) 80017-\mathrm{C}$.

1004 [29] L.H. Ong, M. Dömök, R. Olindo, A.C. van Veen, J.A. Lercher, Dealumination of HZSM-5 1005 via steam-treatment, Microporous Mesoporous Mater. 164 (2012) 9-20. 1006 doi:10.1016/j.micromeso.2012.07.033.

1007 [30] A. Corma, J. Mengual, P.J. Miguel, Stabilization of ZSM-5 zeolite catalysts for steam 1008 catalytic cracking of naphtha for production of propene and ethene, Appl. Catal. A Gen. 
1009 421-422 (2012) 121-134. doi:10.1016/j.apcata.2012.02.008.

1010 [31] H.E. Van Der Bij, F. Meirer, S. Kalirai, J. Wang, B.M. Weckhuysen, Hexane cracking over 1011 steamed phosphated zeolite H-ZSM-5: Promotional effect on catalyst performance and 1012 stability, Chem. - A Eur. J. 20 (2014) 16922-16932. doi:10.1002/chem.201404924.

1013 [32] T.C. Hoff, D.W. Gardner, R. Thilakaratne, K. Wang, T.W. Hansen, R.C. Brown, J.P. 1014 Tessonnier, Tailoring ZSM-5 Zeolites for the Fast Pyrolysis of Biomass to Aromatic 1015 Hydrocarbons, ChemSusChem. 9 (2016) 1473-1482. doi:10.1002/cssc.201600186.

1016 [33] G.W. Huber, United States Patent - Catalytic pyrolysis of solid biomass and related biofuels, 1017 aromatic, and olefin compounds, Patent No.: 8864984 B2, 2014. 1018 doi:10.1074/JBC.274.42.30033.(51).

1019 [34] S. Wan, C. Waters, A. Stevens, A. Gumidyala, R. Jentoft, L. Lobban, D. Resasco, R. 1020 Mallinson, S. Crossley, Decoupling HZSM-5 catalyst activity from deactivation during 1021 upgrading of pyrolysis oil vapors, ChemSusChem. 8 (2015) 552-559. 1022 doi:10.1002/cssc.201402861.

1023 [35] S.A. Channiwala, P.P. Parikh, A unified correlation for estimating HHV of solid, liquid and 1024 gaseous fuels, Fuel. 81 (2002) 1051-1063. doi:10.1016/S0016-2361(01)00131-4.

1025 [36] A. Jensen, K. Dam-Johansen, M.A. Wójtowicz, M.A. Serio, TG-FTIR study of the influence 1026 of potassium chloride on wheat straw pyrolysis, Energy and Fuels. 12 (1998) 929-938. 1027 doi:10.1021/ef980008i.

1028 [37] G. Zhou, P.A. Jensen, D.M. Le, N.O. Knudsen, A.D. Jensen, Direct upgrading of fast 1029 pyrolysis lignin vapor over HZSM-5 catalyst, Green Chem. accepted (2015) DOI: 
$1030 \quad$ 10.1039/c5gc01976a. doi:10.1039/C5GC01976A.

1031 [38] C. S.a, P.P. Parikh, A inified correlation for estimating HHV of solid,liquid and gaseous 1032 fuels, Fuel. 81 (2002) 1051-1063.

1033 [39] K. Schofield, The enigmatic mechanism of the flame ionization detector: Its overlooked 1034 implications for fossil fuel combustion modeling, Prog. Energy Combust. Sci. 34 (2008) 1035 330-350. doi:10.1016/j.pecs.2007.08.001.

1036 [40] J. Ferrell, M. V Olarte, A. Padmaperuma, Development and Standardization of Techniques 1037 for Bio-oil Characterization, (2015).

1038 [41] G.R. Fulmer, A.J.M. Miller, N.H. Sherden, H.E. Gottlieb, A. Nudelman, B.M. Stoltz, J.E. 1039 Bercaw, K.I. Goldberg, NMR chemical shifts of trace impurities: Common laboratory 1040 solvents, organics, and gases in deuterated solvents relevant to the organometallic chemist, 1041 Organometallics. 29 (2010) 2176-2179. doi:10.1021/om100106e.

1042 [42] V. Paasikallio, C. Lindfors, J. Lehto, A. Oasmaa, M. Reinikainen, Short vapour residence 1043 time catalytic pyrolysis of spruce sawdust in a bubbling fluidized-bed reactor with HZSM10445 catalysts, Top. Catal. 56 (2013) 800-812. doi:10.1007/s11244-013-0037-y.

1045 [43] S. Vitolo, B. Bresci, M. Seggiani, M.G. Gallo, Catalytic upgrading of pyrolytic oils over 1046 HZSM-5 zeolite: Behaviour of the catalyst when used in repeated upgrading-regenerating 1047 cycles, Fuel. 80 (2001) 17-26. doi:10.1016/S0016-2361(00)00063-6.

1048 [44] J. Knöll, U. Singh, J. Nicolich, R. Gonzalez, M. Ziebarth, C. Fougret, S. Brandt, Unit cell 1049 volume as a measure of dealumination of ZSM-5 in fluid catalytic cracking catalyst, Ind. $1050 \quad$ Eng. Chem. Res. 53 (2014) 16270-16274. doi:10.1021/ie502522q. 
1051 [45] K. Hemelsoet, J. Van Der Mynsbrugge, K. De Wispelaere, M. Waroquier, V. Van 1052 Speybroeck, Unraveling the reaction mechanisms governing methanol-to-olefins catalysis 1053 by theory and experiment, ChemPhysChem. $14 \quad$ (2013) 1526-1545. 1054 doi:10.1002/cphc.201201023.

1055 [46] J. Sitzmann, Upgrading of Fast Pyrolysis Oils by Hot Filtration, 2009.

1056 [47] A.K. Starace, B.A. Black, D.D. Lee, E.C. Palmiotti, K.A. Orton, W.E. Michener, J. ten 1057 Dam, M.J. Watson, G.T. Beckham, K.A. Magrini, C. Mukarakate, Characterization and 1058 Catalytic Upgrading of Aqueous Stream Carbon from Catalytic Fast Pyrolysis of Biomass, 1059 ACS Sustain. Chem. Eng. (2017) acssuschemeng.7b03344. 1060 doi:10.1021/acssuschemeng.7b03344.

1061 [48] R.H. Venderbosch, A critical view on catalytic pyrolysis of biomass, ChemSusChem. 8 1062 (2015) 1306-1316. doi:10.1002/cssc.201500115.

1063 [49] P. Leflaive, J.L. Lemberton, G. Pérot, C. Mirgain, J.Y. Carriat, J.M. Colin, On the origin of 1064 sulfur impurities in fluid catalytic cracking gasoline - Reactivity of thiophene derivatives 1065 and of their possible precursors under FCC conditions, Appl. Catal. A Gen. 227 (2002) 2011066 215. doi:10.1016/S0926-860X(01)00936-X.

1067 [50] T.P. Vispute, H. Zhang, A. Sanna, R. Xiao, G.W. Huber, Renewable chemical commodity 1068 feedstocks from integrated catalytic processing of pyrolysis oils, Science. 330 (2010) 12221069 1227. doi:10.1126/science. 1194218.

1070 [51] T.N. Trinh, P.A. Jensen, D.J. Kim, N.O. Knudsen, H.R. Sørensen, S. Hvilsted, Comparison 1071 of lignin, macroalgae, wood, and straw fast pyrolysis, Energy and Fuels. 27 (2013) 1399- 
1072 1409. doi:10.1021/ef301927y.

1073 [52] A. V. Bridgwater, Review of fast pyrolysis of biomass and product upgrading, Biomass and 1074 Bioenergy. 38 (2012) 68-94. doi:10.1016/j.biombioe.2011.01.048.

1075

[53] S. Czernik, A. V. Bridgwater, Overview of applications of biomass fast pyrolysis oil, 1076 Energy \& Fuels. 18 (2004) 590-598. doi:10.1021/ef034067u.

1077

[54] H. Yang, R.J. Coolman, P. Karanjkar, H. Wang, Z. Xu, H. Chen, T.J. Moutziaris, G.W. 1078 Huber, The effect of steam on the catalytic fast pyrolysis of cellulose, Green Chem. 17 1079 (2016) 2912-2923. doi:10.1039/C5GC00026B.

1080

[55] 1081

1082 1083

D.C. Dayton, T. Member, A. Daniels, M. Company, Catalytic Deoxygenation of Biomass Pyrolysis Vapors to Improve Bio-oil Stability Award Number: DE-FG36-08GO18208 Recipient : RTI International Project Location : Research Triangle Park, NC 27709 Projec, (n.d.).

1085

1086

O. Mante, F.A. Agblevor, S.T. Oyama, R. McClung, The effect of hydrothermal treatment of FCC catalysts and ZSM-5 additives in catalytic conversion of biomass, Appl. Catal. A Gen. 445-446 (2012) 312-320. doi:10.1016/j.apcata.2012.08.039.

[57] J. Joseph, C. Baker, S. Mukkamala, S.H. Beis, M.C. Wheeler, W.J. DeSisto, B.L. Jensen, B.G. Frederick, Chemical Shifts and Lifetimes for Nuclear Magnetic Resonance (NMR) Analysis of Biofuels, Energy \& Fuels. 24 (2010) 5153-5162. doi:10.1021/ef100504d.

[58] N. Hao, H. Ben, C.G. Yoo, S. Adhikari, A.J. Ragauskas, Review of NMR Characterization of Pyrolysis Oils, Energy and Fuels. 30 (2016) 6863-6880. doi:10.1021/acs.energyfuels.6b01002. 
1093 [59] J. Fermoso, H. Hernando, S. Jiménez-Sánchez, A.A. Lappas, E. Heracleous, P. Pizarro, J.M. 1094 Coronado, D.P. Serrano, Bio-oil production by lignocellulose fast-pyrolysis: Isolating and 1095 comparing the effects of indigenous versus external catalysts, Fuel Process. Technol. 167 1096 (2017) 563-574. doi:10.1016/j.fuproc.2017.08.009.

1097 [60] H. Hernando, S. Jiménez-Sánchez, J. Fermoso, P. Pizarro, J.M. Coronado, D.P. Serrano, 1098 Assessing biomass catalytic pyrolysis in terms of deoxygenation pathways and energy $1099 \quad$ yields for the efficient production of advanced biofuels, Catal. Sci. Technol. 6 (2016) 28291100 2843. doi:10.1039/c6cy00522e.

1101 [61] C. Lindfors, V. Paasikallio, E. Kuoppala, M. Reinikainen, A. Oasmaa, Y. Solantausta, Co1102 processing of dry bio-oil, catalytic pyrolysis oil, and hydrotreated bio-oil in a micro activity 1103 test unit, Energy and Fuels. 29 (2015) 3707-3714. doi:10.1021/acs.energyfuels.5b00339.

1104 [62] A. de Rezende Pinho, M.B.B. de Almeida, F.L. Mendes, V.L. Ximenes, Production of 1105 lignocellulosic gasoline using fast pyrolysis of biomass and a conventional refining scheme, 1106 Pure Appl. Chem. 86 (2014). doi:10.1515/pac-2013-0914. 